Document downloaded from:

http://hdl.handle.net/10251/136500

This paper must be cited as:

Mundi, I.; Alemany Díaz, MDM.; Poler, R.; Fuertes-Miquel, VS. (2019). Review of mathematical models for production planning under uncertainty due to lack of homogeneity: proposal of a conceptual model. International Journal of Production Research. 57(15-16):5239-5283. https://doi.org/10.1080/00207543.2019.1566665

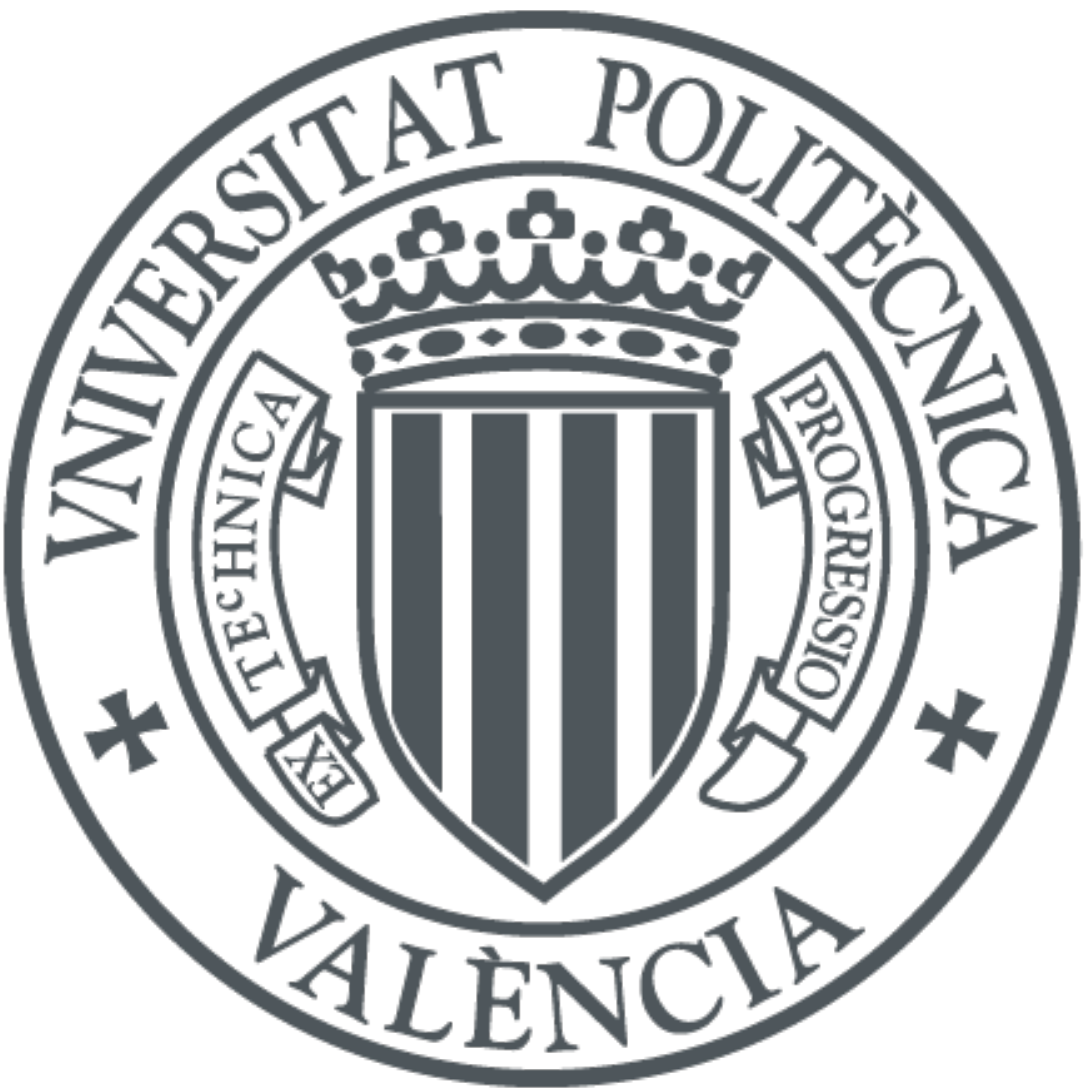

The final publication is available at

https://doi.org/10.1080/00207543.2019.1566665

Copyright Taylor \& Francis

Additional Information 


\title{
Review of mathematical models for production planning under uncertainty due to lack of homogeneity. Proposal of a conceptual model
}

\begin{abstract}
Lack of homogeneity in the product (LHP) appears in some production processes that confer heterogeneity in the characteristics of the products obtained. Supply chains with this issue have to classify the product in different homogeneous subsets, whose quantity is uncertain during the production planning process. This paper proposes a generic framework for reviewing in a unified way the literature about production planning models dealing with LHP uncertainty. This analysis allows the identification of: similarities among sectors to transfer solutions between them and gaps existing in the literature for further research. The results of the review show: 1) sectors affected by LHP inherent uncertainty, 2) the inherent LHP uncertainty types modelled, and 3) the approaches for modelling LHP uncertainty most widely employed. Finally, we suggest a conceptual model reflecting the aspects to be considered when modelling the production planning in sectors with LHP in an uncertain environment.
\end{abstract}

Keywords: planning, optimization, production, uncertainty, mathematical modelling

\section{Introduction}

Production Planning is considered one of the most important processes to balance efficiently supply and demand in terms of quantity and due dates. However, there are some situations where customers additionally require homogeneity among units of their orders. This is the case of companies that incorporate raw materials directly obtained from nature and/or production processes that cause heterogeneity in the characteristics of the items obtained, even when the used materials are homogeneous (Alemany et al., 2013). This lack of homogeneity becomes a problem when customers require homogeneity between units of finished goods as regards certain product attributes because they have to be jointly used, shown, placed or consumed (Alarcón et al., 2011). 
For example, in the agri-food sector, fruits are non-homogeneous in terms of size, weight, colour and quality so their classification is necessary to satisfy commercial retail formats. Along these lines, Grillo et al. (2017) classify units of finished goods in fruit supply chains according to their variety, quality, calibre, packaging type and harvesting time (shelf-life) to accomplish with customer homogeneity requirements.

Alarcón et al. (2011) define the lack of homogeneity in the product as "the absence of the homogeneity requested by the customer in the products". In this paper, the LHP definition above is extended to "the absence of homogeneity in units of the same item at any stage of the transformation process which should be managed in order to meet customer's requirement of homogeneity in finished goods". LHP can appear in raw materials directly obtained from the nature (LHRM), and/or in intermediate products (LHI) due to the lack of homogeneity in raw material (LHRM) and/or operations which confer heterogeneity upon the items obtained, even when the inputs used are homogeneous. This heterogeneity can be transferred until the finished product, giving rise to lack of homogeneity in the product (LHP). This will be the case, for example, of ceramic pieces which present different qualities, tones and gages. However, there are situations in which lack of homogeneity in raw material (LHRM) and /or in the intermediate products (LHI) can be eliminated by the appropriate management of the manufacturing process. For these cases, the finished good obtained is homogeneous and therefore there will be not lack of homogeneity in the product. For instance, in the petroleum industry there is lack of homogeneity in raw material (LHRM), due to raw material composition. But the manufacturing process removes it, so LHP does not exist in the finished good. However, lack of homogeneity in raw material (LHRM) and /or in the intermediate products (LHI) appears in this sector so we will consider it in order to assess how LHP characteristics are modelled. 
LHP is present in several industries such as mining, ceramic, wood, food or textile. In companies of these sectors the planning process becomes more complex due to the following reasons (Alemany et al., 2013). 1) LHP increases the volume of references to be managed: with the aim of complying with customer requirements, these companies are obliged to include some classification stages for sorting quantities of the same item into homogeneous subsets (subtypes) based on certain attributes that are relevant to the customer. Classifying one same item into several subtypes increases the number of references and the information volume to be processed, which complicates system management. 2) LHP introduces different sources of uncertainty not present in other production planning processes that need to be categorized prior to manage them. For instance, after each classification stage, the quantity of each subtype will only be known subsequent to the production is finished and items are classified. Therefore, these companies will face a new kind of LHP inherent uncertainty: uncertainty in the quantities of each subtype in different lots. 3) Finally, homogeneity requirements of customers introduce new constraints to be taken into account to not worsen the customer service and satisfaction level.

Poor LHP management may have very negative effects on supply chains' (SC) competitiveness: (1) LHP leads to fragmented stocks, which can rapidly become obsolete for products with a short life cycle as they cannot be accumulated to be used in the same order given their heterogeneity; (2) uncertainty in the homogeneous quantities (subtypes) available of finished goods (FGs) entails having to produce more than is necessary, thus increasing stocks; and (3) the customer service level may prove deficient, even with high stock volumes if the subtypes quantities obtained during the production process and defined in the master plan do not match with those required by customers. 
To avoid these undesirable effects, the consideration of the LHP characteristics in the production planning process becomes crucial. Production planning is one of the most important SC activities to short-medium term, and it is one of the main inputs to the order promising process. Thus, the master plan should consider LHP characteristics in order to provide reliable information about future available homogeneous quantities to the order promising process to comply with customer homogeneity requirements. The inclusion of LHP characteristics in production planning leads to modelling LHP uncertainty. SCs with LHP have unique characteristics and sources of uncertainty that differ from those of other SCs. Van der Vorst (2000) defines the inherent sources of uncertainty as those originated by the natural physical characteristics of the SC, and identifies three possible causes:

(1) Intrinsic features of products which, in LHP contexts, are caused by the nonhomogeneity of the raw materials obtained directly from nature.

(2) Technological characteristics of the processes which, in LHP contexts, are characterised by the existence of uncontrollable factors during transformation activities (such as humidity, temperature, etc.) affecting some attributes of the finished goods.

(3) Characteristics of logistics actors which refer to customer preferences in some attributes of the finished products and, therefore, into subtypes (e.g. due to the eating habits of the customers).

It can be stated that LHP introduces complex aspects related to materials, transformation activities and characteristics of customer orders. These aspects confer unique characteristics with inherent uncertainty sources to SC with LHP. Although various sectors are affected by LHP and its negative consequences, there is a lack of literature dealing with LHP uncertainty in most of them. This requires analysing how 
LHP is modelled at the production planning level in different sectors under a common perspective, with the aim of transferring the valid proposals made in a specific sector to others ones in which LHP characteristics have been treated in minority. We propose a common framework to analyse the literature about mathematical programming models for production planning in an uncertain environment which include some LHP characteristic. This analysis will be summarized later in a conceptual model that can be used as a reference model to practitioners and researchers.

A Conceptual Model is a set of concepts employed to represent or describe an event, object or process and can be based on the integration of different works on the same topic (Meredith, 1993). Several authors use a systematic review of the literature to propose a conceptual model which integrates the most important concepts in different field (Heckmann et al., 2015; Igarashi et al., 2013; Ramasesh and Browning, 2014; Seth et al., 2006). We suggest a conceptual model based on the literature review whose systematic analysis brings together the aspects to consider when modelling the production planning in sectors with LHP in an uncertain environment.

Thus, the main objectives of this paper are to: 1) review and discuss the LHP characteristics handled in production planning models in an uncertainty context under a sector perspective; 2) provide insights to deal with LHP in a unified way; 3 ) characterise LHP inherent uncertainty through an abstraction of the common LHP uncertain characteristics in different sectors capturing it in a conceptual model; and 4) find existing gaps in the literature for future research.

The rest of the paper is structured as follows: Section 2 exposes the research methodology followed in this paper. Section 3 describes the proposed analysis framework to review the literature. In Section 4, models are classified according to the defined analysis framework by differentiating into sectors. Section 5 suggests a 
conceptual model based on the analysis of literature. Finally, Section 6 reports the conclusions derived from the obtained results and future research directions.

\section{Research methodology}

Seuring and Müller (2008) underline that literature reviews are intended to summarize the existing research by identifying patterns which helps to identify the conceptual content of the field (Meredith, 1993) and can contribute to the development of the theory. Following the review methodology successfully used in other papers (Seuring and Müller, 2008; Alfalla-Luque et al., 2012; Igarashi et al., 2013), the first step is to define and delimit the collection of material. The following describes the general aspects (such as publications per year, etc.) and specific aspects or categories to analyse the collected material (based on search terms). Then the papers are classified and analysed according to the defined categories. We describe collection of material and analyse the general aspects in this section and we analyse the papers from standpoint the specific categories in section 3 by defining an analysis framework.

The search process was carried out in last-2018, being the researched period 1995-2018 and using scientific-technical bibliographic databases, such as Web of Science, Science Direct, IEEE Xplore, Business Premier, Google Academic and Scopus. The search terms refer to the purpose of the review, that is, how LHP characteristics and its inherent uncertainty are integrated in a mathematical model at production planning level in different sectors. Thus, they include four categories relating to: (1) SC planning, (2) uncertainty, (3) LHP characteristics and (4) sectors with LHP.

(1) SC planning: supply chain planning, master planning, operation planning, production planning and network planning. 
(4) Uncertainty: uncertain, stochastic, probabilistic and fuzzy.

(5) LHP characteristics: heterogeneity, homogeneity, divergent process, rBOM (reverse bill of materials), classification, sorting, grading, scrap, waste, subtype and quality.

(6) LHP sectors: ceramic, tile, textile, wood, lumber, marble, tanned hide, fur, leather, horticulture, agricultural, fruit, vegetable, petroleum, oil, steel, food, jewel, meat, furniture.

After excluding unrelated fields and reading the title and abstract, nearly 200 references were selected. In this first filtering step, we ruled out those articles that were focused exclusively on the strategic decision level or scheduling level, and the supply network design. Therefore, the papers selected in the first step were centred on production planning models in an uncertain context. In a second step, only those references that modelled some LHP characteristics were chosen. Among these papers, some simulation models were discarded because they were not mathematical models (Gallo et al., 2009; Pitty et al., 2008; Poles and Cheong, 2009). As a result, 87 references were elected for this research, which also included some referenced works in the analysed papers that we considered very suitable for this paper.

We use the following category of general classification for the review of relevant literature: distribution of papers per year of publication. The papers reviewed by year are displayed in Figure 1. As seen, the amount of published papers increases with time; around $80 \%$ of the papers have been published over the last 10 years. It should be noted that the largest number of publications was located between 2010 and 2012. 


\section{Analysis Framework}

To systematically study the multiple references found in the literature, an analysis framework is proposed (Figure 2) that is based on Mula et al. (2010a) and Peidró et al. (2009), but with some differences in order to reflect the LHP characteristics. Three blocks compose the analysis framework: environment, uncertainty and model. As Mula et al. (2010a), we identify the environment in which the documents analysed are developed. However, different dimensions for the environment have been considered in our case: sector and LHP characteristics. Then, a new block named uncertainty is proposed to include those environmental characteristics modelled in an uncertainty way (uncertainty studied) and, more especially, those related with LHP (LHP inherent uncertainty) as well as the uncertainty approach used. Finally, as regards the model dimension and, as Peidro et al. (2009), we also identify the modelling approach used by the authors. Besides, we include two new elements: objective/s and LHP modelling. The aim of these two last elements is to provide insights about how the LHP characteristics and its inherent uncertainty have been integrated in mathematical models. Below, each dimension of the analysis framework is described in more detail.

\section{Environment}

The way the LHP occurs, depends mainly on the sector, supply chain and product. One of the main contributions of this review is its focus on sectors that provide a general framework for the transfer of valid proposals made in a specific sector to others. The analysis of the different selected references is presented by sector in order to clearly show which LHP characteristics appear and have been modelled in each one.

By identifying LHP characteristics that appear in each sector, it is possible to determine the most modelled ones in the literature, as well as any existing gaps for 
future research. In this study, we focus on those LHP aspects that are relevant to characterise LHP for planning purposes. Along these lines, the most important LHP aspect that influences the SC Production Planning is the existence of references of the same LHP-item, but with different characteristics (subtypes). When customers require that their orders are served with homogeneous units, LHP SCs are obliged to include one or more sorting stages during the production process whose location and classification criteria depend on the specific industry. For each classified item, the classification attributes and values that they can take should be identified. These items are sorted into subtypes, defined as units of the same LHP-item with the same value of the classification attributes previously defined. For example, in the agricultural sector, fruits are classified according to size, color and quality into different subtypes and quantities (subtype quantity). Furthermore, subtypes for an item can have the same or a different economic value (subtype value). Different economic values usually involve the existence of several qualities. Another aspect is that the value of the classification attributes (subtype state) may remain unchanged over time (static) or not (dynamic). For example, in the food sector, freshness decreases with time (decay).

The appearance of subtypes increases the volume of information to be managed and adds new constraints and possibilities of serving customer demand, thus increasing the complexity of SC Production Planning. Therefore, the relevant LHP characteristics considered to analyse the selected papers are:

- Number of Subtypes (S.): The total number of existing subtypes of each LHPitem depends on the attributes used in the classification stage and their possible values. For instance, in the ceramics sector, each piece has to be inspected and classified, and individual models (products) are usually stored in homogeneous subgroups (subtypes) according to quality (aspect), tone (degree of colour) and 
calibre (thickness) (Alemany et al., 2018; Alarcón et al., 2011; Davoli et al., 2010). The usual consideration of three quality grades, two tones and three calibres in the same model (finished good) could add up 13 different references. Finally, the number of subtypes that appears in each supplied, produced or distributed quantity can be fixed or variable, depending on the product. For instance, in the ceramics sector, the number and subtypes appearing in each lot is variable.

- Subtype Quantity (S. Qty): It refers to the quantity obtained of each subtype between lots or in the same lot. Although the final quantity obtained of each subtype can depend on lot size, its proportion can also be fixed or variable.

- Subtype Value (S. Value): It concerns the economic value or utility given by the buyer for the different subtypes of a LHP-item. Each subtype value can be the same or different. Different values for each subtype usually imply the existence of different qualities and/or amounts of disposable products (scrap with a null value).

- Subtype State (S.State): The value of classification attributes of an item in a particular subtype can be dynamic (if changes over time) or static (if not change over time). For example, in the food sector, products can be perishable; i.e. quality (freshness) decreases over time (decay).

Based on the above definitions, it is important to note that the existence of Subtype Quantity and/or Subtype Value and/or Subtype State implies the existence of Subtypes. However, this classification is needed to identify accurately the LHP uncertainty addressed by each paper as there may be uncertainties in Subtype Quantity and/or Subtype Value and/or Subtype State, but not in Subtypes. 


\section{Uncertainty}

In the block called "uncertainty", we capture the aspects that have been modelled under uncertainty. We distinguish three dimensions: uncertainty studied, LHP inherent uncertainty and uncertainty approach. On the one hand, we name "uncertainty studied" to the uncertainty addressed by the authors in their work. If the authors include some LHP characteristic in the "uncertainty studied", we say that this is "LHP inherent uncertainty".

With the aim of analysing in a structured and precise way how the "LHP inherent uncertainty" has been modelled in SCs, we define the so called "LHP inherent uncertainty types". To characterise them, we consider two dimensions (Figure 3): the uncertainty types and the LHP aspects. Across the board, the types of uncertainty that are considered in the literature are (Peidro et al., 2009; Graves, 2011): a) Supply uncertainty; b) Process uncertainty; and c) Demand uncertainty. The sources of inherent uncertainty in LHP SCs affect four main aspects of relevance for planning purposes, which coincide with the four LHP characteristics from the previous section: the number of subtypes (S.), the quantities of each subtype (S.Qty), the subtype value (S.Value) and the subtype state (S.State). In this paper, we define twelve "LHP inherent uncertainty types", which are the result of combining the four LHP characteristics with the three main types of uncertainty (Figure 3).

Therefore, we present the aspects that have been modelled under uncertainty in every paper in the dimension "uncertainty studied ". We discuss whether this uncertainty corresponds to some LHP Characteristics. If so, we classify it in one of twelve predefined "LHP inherent uncertainty types". This abstraction allows comparison between sectors in a unified language, making it possible to transfer the know-how from one sector to another. 
The uncertainty approach dimension used to introduce uncertainty into the models distinguishes the following proposals to model uncertainty (Lalmazloumian and Wong, 2012):

- Distribution-based approach (Distibution), where statistical distributions are used to model uncertainty in some parameter.

- Fuzzy-based approach (Fuzzy), where uncertain parameters are considered fuzzy numbers.

- Scenario-based approach (Scenario), in which several discrete scenarios with associated probability levels are used to describe the expected occurrence of particular outcomes.

\section{Model}

In the "model" block, we focus on the modelling approach used, the objective/s of the model and how the LHP characteristics and LHP inherent uncertainty types have been introduced into the model (LHP modelling). The considered modelling approaches are based on those of Mula et al. (2010a). Hybrid models refer to the papers that combine some of the above approaches with simulation models. The codes provided for each modelling approach are shown in Figure 4.

\section{Literature review}

In this section, the analysis of the different selected references is presented by sector for the purpose of clearly showing which LHP characteristics appear and have been modelled in each one.

The papers dealing with LHP uncertainty in the agri-food sector and remanufacturing sector are the most abundant $23 \%$ each one), followed by petroleum 
sector (18.8\%). These three sectors account for over $64 \%$ of the references analysed.

Other sectors studied are mining, wood and ceramic. Sectors in which the sample is not representative (one paper) or papers in which the authors present a generic case not making reference to any specific sector are shown separately.

\section{Petroleum sector}

Petroleum refinery is one of the most important industries, which comprises many different and complicated processes. Conversion of crude oil into more valuable products involves many processes, each of which is very complex. Crude oil can be blended with a wide range of other crude oils and it can be processed differently depending on the refinery configuration for a given product demand (Gupta and Nan, 2006). Crude oil can be purchased anywhere in the world and it is possible to acquire a broad variety of grades of crude oil (S.) in different quantities (S.Qty), which are differentiated according to the following attributes: compositions, yields and characteristics. Depending on sort of crude oil, refineries produce different quotas of products like gasoline, diesel, heating oil, kerosene, liquid gas, as well as bitumen or petrochemical products like ethylene and propylene. On the other hand, the oil market is a global market. The prices for raw materials (crude and semi-finished products) are highly volatile and are strongly driven by the market and its environment, but the local price fixing is possible based on its properties (S.Value) (Roitsch and Meyr, 2008). Thus in the petroleum sector, the appearance of subtypes (S.) comes about by the occurrence of different crude qualities (in supply and process) due to their compositions or characteristics, which are manifested in different quantities or yields (S.Qty), and which can also take a different value (S.Value).

The reviewed papers relating to the petroleum sector are classified in Table 1 . As it can be observed, the only LHP characteristics discussed in the papers are the 
number of subtypes (S.) and subtype quantities (S.Qty) due to the different compositions of raw materials (crude oil) or intermediate products, which give rise to different yields (S.Qty) according to the transformation process involved. Although Subtype Value (S. Value) may appear, none distinguishes subtypes with different economic values.

With regard to uncertainty in the petroleum sector, Khor (2007) classifies possible uncertainty factors in the planning of a refinery as factors exogenous (external) and endogenous factors (internal).

As shown in the "Uncertainty studied" column, most of the reviewed papers analyse external uncertainties: demands and prices. The papers consider external uncertainties in operation costs, delays, inventory costs and inventory levels, to a lesser extent. Internal uncertainties in supply, yields and capacity due to composition of raw materials are also considered.

When comparing the "LHP Characteristics" modelled with "Uncertainty studied" by the authors the only LHP inherent uncertainty types that appear are SupplyS.Qty and Process-S.Qty. The main LHP uncertainty type modelled is Process-S.Qty (in 6 of 16 papers); i.e., quantities per subtype (S.Qty) in the process are variable and not known with certainty mainly due to the yield, but it is also due to the splitting process and to specifications of final goods. Three papers deal with Supply-S.Qty due to composition of raw materials (in 3 of 16 papers). Despite the "Uncertainty studied" on demand appearing in some cases, none deals with LHP inherent uncertainty on demand because the subtypes are classified in the supply or in the process, not being the final goods differentiated by subtypes. When the LHP characteristic is not considered from the uncertainty point of view, no concept appears in the "LHP inherent uncertainty" column (in 7 of 16 papers). It is noteworthy that although the number of subtypes (S.) 
appears as a LHP characteristic, it is always considered constant and known with certainty, so it is not considered to be LHP uncertainty.

Furthermore, from a point of view of the "Uncertainty approach", the most widely used approach is Scenario-Based Approach (in 13 of 16 papers). There are only two papers that use the Fuzzy-Based Approach and only one employs DistributionBased Approach.

From the "Modelling approach" perspective, the most used one is Stochastic Programming (SP) (in 8 of 16 papers). Four papers suggest Linear Programming (LP) models and three of them use Non-linear Programming. There is only one paper that uses Multi-objective linear programming (MOLP) whose goals are defined by ratios to maximise profit and to minimise capacity. It is noted that none uses Fuzzy Programming (FP).

The majority of the papers (15) take into account only one objective that is manly related with the maximization of profits, revenues or gross margin followed by the minimization of costs. Only one paper aims to optimize more than one objective by means a MOLP approach.

Regarding how the LHP has been modelled ("LHP Modelling"), the models define parameters that represent the yields of the processes or the subtype quantities due to the different compositions of raw materials or intermediate products. Mainly, there are restrictions of material balance and/or restrictions that specify the maximum and minimum limits among which there should be some characteristic. Some models take into account legislation requirements.

\section{Agri-food sector}

Hovelaque et al. (2009) claim that the design of a specific food supply chain depends on the live nature of the products. Firms find it difficult to forecast their supplies because 
of the heterogeneous quality of raw materials (S.) brought about by agronomic and climatic factors. Furthermore, yields are uncertain (S.Qty) as it is very difficult to know the available raw material quantities with certainty before harvests for some (i.e., for seasonal products like potatoes), and the timing and quantity of delivery for other (i.e., milk and meat). Van Wezel et al. (2006) describe the organizational and logistical characteristics in this kind of industry as well as the way in which planning processes are usually organized. Van Donk (2000) highlights that food processing industries process natural materials which vary in quality and composition (S.). Therefore, processes might be uncontrollable in terms of their yield or quality of output (S.Qty). Moreover, products might easily become obsolete due to their limited shelf lives (S.State). Ahumada and Villalobos (2009) distinguish between two main types of SC in the agri-food industry. The first is the fresh agri-foods SC, which are highly perishable (S.State), such as fresh fruits and vegetables, whose shelf life can be measured in days. The second one is the for non-perishable agri-foods $\mathrm{SC}$ which can be stored for longer periods of time, such as grains, potatoes and nuts, but are perishable if not stored properly.

Moreover, the variable quality of the raw material (S.) often leads to variations in the quantities used to produce a product (S.Qty). For example, the fat content of raw milk depends on the seasonality or the weight and size of animals which, in turn, depends on the feed provided by farmers. This variability can lead to recipe variations in order to keep the quality and characteristics of the finished product stable. The recipe has to provide certain flexibility in the choice of raw materials and the quantities used. In addition, the available quantities of the raw material can vary significantly over time, which implies that the price of raw materials may also vary (Entrup, 2005). Thus, in the agri-food sector, these characteristics can imply the appearance of subtypes (S.) based 
on their heterogeneous quality and composition of raw materials, variable supply (S.Qty), heterogeneous quality (S.Value) and perishability (S.State). These features are often ignored or used as "mean" or "most likely" value for production planning (Bohle et al., 2010; Entrup, 2005). Furthermore, it is intended that the stocks stay low to avoid the risk of obsolescence (Entrup, 2005).

The reviewed papers relating to the agri-food sector are provided in Table 2 . The main "LHP Characteristic" modelled is subtype quantities due to raw materials quality and/or crop yields (in 14 of 20), followed closely by perishability due to the quality and/or composition of raw materials (in 11 of 20). It should be mentioned that Schutz and Tomasgard (2011) consider a splitting process (meat) whose yield (S.Qty) depends on the used rBOM (cutting patterns) and the used recipe. Bertrand and Rutten (1999), Hovelaque et al. (2009) and Munhoz and Morabito (2014) consider variations in recipes (S.Qty) in order to keep the quality and characteristics of the finished product stable. Radulescu et al. (2008) are the only one that take into account both yields (SQ) and different prices for each subtype (S.Value).

Esteso et al. (2018) provides a detailed description about the uncertainties that can appear in the agri-food SCs. Van der Vorst and Beulens (2002) categorise uncertainty sources in these SCs as:

(1) Inherent characteristics that cause more or less predictable fluctuations due to specific product and process characteristics, such as perishability, variable harvest (and variable quality) and production yields (and scrap rates).

(2) Features that result in potential disturbances of system performance (for example, wrong decision rules applied, inflexible capacities or information delays). 
(3) Exogenous phenomena that disturb the system such as changes in markets, products, technology, competitors and governmental regulations.

As shown in the "Uncertainty studied" column, the papers deal with the uncertainty demand and prices (exogenous phenomena), quantities, qualities and prices in supply due to variability in raw materials and yields due to product yields (inherent characteristics). Other considered uncertainties are harvest time, packing rate, shortage cost and labor availability, which affect product perishability (inherent characteristics).

When comparing the modelled "LHP Characteristics" with "Uncertainty studied”, we identify "LHP inherent uncertainty” types. They mainly appear in supply (9 papers) and process ( 4 papers). Eight of the reviewed papers analyse quantities per subtype in Supply (Supply-S.Qty) due to quality and composition of raw materials (final goods are not differentiated by subtypes). Only one paper (Miller et al., 1997) deals with perishability in supply from an uncertain standpoint (Supply-S.State). Four papers consider "LHP Inherent Uncertainty" in the process. Radulescu et al. (2008) deal with LHP Uncertainty in the process caused by crop yields (Process-S.Qty) and their values (prices) (Process-S.Value), while Bohle et al. (2010), Sel and Bloemhof-Ruwaard (2017) and Begen and Puterman (2003) also deal with LHP Uncertainty in the process, but that caused by perishability (Process-S.State). Bohle et al. (2010) consider uncertainty in labour availability to harvest and Begen and Puterman (2003) deal with LHP Inherent Uncertainty in the process caused by perishability (Process-S.State) due to uncertainty in the capacity to process the complete daily catch (fish quality deteriorates with time). The remainder papers do not consider any LHP characteristic from the uncertain standpoint. Only one paper deals with LHP Inherent Uncertainty on demand (Sel et al., 2017). Although the number of subtypes (S.) appears as an LHP 
characteristic, it is always considered constant and known with certainty, so it is not considered LHP uncertainty.

From the standpoint "Uncertainty approach", fifteen papers use Scenario-Based Approach (75\%). The Distribution-Based Approach is only used in three papers (15\%), and two others employ the Fuzzy-Based Approach (10\%).

Different "Modelling approaches" are adopted, of which Stochastic Programming (in 8 of 20 papers) is mostly used, followed by Linear programming (LP) (in 5 of 20 papers). There is one paper that employs Fuzzy Programming (FP), another uses Non-linear Programming (NLP) and two works consider Multi-objective programming (MOLP). Hybrid Models (HYB) are used in three works (3 of 20 papers).

The majority of the papers consider only one objective (18 papers) related to the minimization of costs, followed by maximization of profits and one of them is related to the minimization the production makespan. Two papers aim to optimize more than one objective that use a MOLP approach, one of them takes into account the environmental impact and the other the average loss.

In relation to the "LHP Modelling", the models define parameters that represent subtype quantities due to raw materials quality and/or crop yields with balance constraints and the upper and lower bounds among which there should be some feature. Perishability is modelled through deterioration constraints or maximum allowed storage time constraints.

\section{Remanufacturing}

Remanufacturing sector includes closed-loop SCs, reverse SCs and remanufacturing with component recovery. According to Junior and Filho (2012), remanufacturing is the process that recovers value from used products by replacing components or reprocessing used parts in order to confer the product a like-new condition. Production 
planning and control activities in remanufacturing can differ vastly from those in traditional manufacturing. Remanufacturing activity brings many challenges to the production and inventory planning problem (Shi et al., 2011). Operational issues in remanufacturing are focused on reverse logistics, testing, sorting, disposition, disassembling, repairing and remanufacturing (Loomba and Nakashima, 2012). In a process environment, French and LaForge (2006) highlight that returned products can be obsolete or have exceeded their shelf-life (S. State). The most important LHP characteristic in this sector is quality of returns (S.): when returns arrive, they are subject to quality inspection and are classified and grouped into several quality grades (e.g. good, average and bad or recovery and disposal). In addition, the different levels of quality defined can involve a distinct cost or value (S.Value). Thus in the remanufacturing sector, the appearance of subtypes (S.) occurs due to the occurrence of different qualities which are evidenced as different amounts (S.Qty) or states (S.State) which may also have a distinct value (S.Value).

Based on this, the reviewed papers relating to the remanufacturing sector are classified in Table 3. The main "LHP Characteristic" modelled is quality of returns due to the necessary classification of returned items. This classification is based on different categories (S.), which appears in different quantities (S.Qty). Olivetti et al. (2011) are the only authors who have classified the raw materials obtained from scrap metal into subtypes (S.) based on their composition instead of their quality. Only one paper (Zeballos et al., 2012) distinguishes quality levels of returns with different economic values (S.Value). Although Subtype State may appear, none considers it in the model. As regards uncertainty, the majority of remanufacturing firms use simple averages to calculate material recovery rates. Nevertheless, the variability in returned product quality remains as a significant problem (Aras et al., 2004). Guide (2000) states 
that the major complicating characteristics are: uncertain timing and quantity of returns, uncertainty in the materials recovered from returned items, disassembly of returned products and stochastic routings and highly variable processing times.

As it can be observed in the "Uncertainty studied", most of the reviewed papers study uncertainty in any of the major complicating characteristics indicated by Guide (2000): quantity and quality of returns, arriving times and process time of returns. Likewise, ten authors deal with uncertain demand (Aras et al., 2004; Shi et al., 2011; Amaro and Barbosa-Povoa, 2009; Loomba and Nakashima, 2012; Jin et al., 2013; Phuc et al., 2013; Liao et al., 2017; Macedo et al., 2015; Moghaddam, 2015; Jindal and Sangwan, 2017). Only Amaro and Barbosa-Povoa (2009) consider uncertainty in finished goods prices, and only Olivetti et al. (2011) model the uncertainty of raw materials composition (scrap metal), which should be used to generate finished goods with certain quality specifications.

When comparing the "LHP characteristic" and the "Uncertainty studied", it is possible to identify the "LHP inherent uncertainty" types modelled in some papers. The main LHP inherent uncertainty type modelled in this sector is the uncertain variability of quantities per subtype in the Supply stage (Supply-S.Qty) (13 papers) due to quality of returns. Only Jindal and Sangwan (2017) model the uncertain variability of quantities per subtype in the process stage (Process-S.Qty). Neither the uncertainty in the number of qualities obtained (S.) nor the uncertainty in their value (S.Value) or their shelf-life (S.State) are considered.

It is worth stressing that although in some papers the "Uncertainty studied" appears in the process or demand (i.e., Aras et al., 2004; Amaro and Barbosa-Povoa, 2009; Loomba and Nakashima, 2012), none deals with LHP inherent uncertainty because returns are classified in supply whereas finished goods are not classified by 
subtypes. Moreover, only Zeballos et al. (2012) consider S.Value as LHP characteristic, but they do not deal with it from a standpoint uncertain. Although the number of subtypes (S.) appears as an LHP characteristic, again it is always considered constant and known with certainty. Finally, we found seven papers dealing with LHP characteristics, but they do not model them from a point of view uncertain (Amaro and Barbosa-Povoa, 2009; Loomba and Nakashima, 2012; Jin et al., 2013; Su and Lin, 2014; Cai et al., 2014; Yazici et al, 2016; Moghaddam, 2015).

Furthermore, the most widely used "uncertainty approach" is Scenario-Based Approach (45\%), followed by Distribution-Based Approach (30\%). Five papers use the Fuzzy-Based Approach (25\%).

The most used modelling approach is Stochastic Programming (SP) (in 7 of 20 papers), followed by Non-linear Programming (in 5 of 20 papers) and Linear Programming (in 4 of 20 papers). There are two papers which use Fuzzy Programming (FP) and two others that suggest the Multi-objective programming (MOLP).

Papers mainly consider one objective (20 papers) related to the minimization of costs, followed by maximization of profits. Two papers aim to optimize more than one objective and use a MOLP approach. These models, in addition to considering the maximization of the profit, one of them proposes the minimization of the environmental impact and the other minimizes the defective parts, the due dates and the risk factors associated with each supplier.

Regarding the LHP modelling, the models establish parameters that define the fraction of returns with a specific quality that are applied to obtain quantities of each quality. In general constraints of material balance are set.

\section{Wood sector}

According to the analysis conducted by Björheden et al. (2005), timber is a 
heterogeneous product in terms of quality. The dimensions, species and quality of inbound sawlogs have a decisive impact on the production range. Zanjani et al. (2010a) state that logs are grown under uncertain natural non-homogeneous circumstances with random characteristics (in terms of diameter, number of knots, internal defects, etc.). The natural variable conditions occurring during the growth period of trees make it impossible to anticipate the exact yields of logs. Consequently, due to non-homogeneity in the characteristics of logs $(\mathbf{S}$.), the process yields, that is, the quantities of lumbers that can be produced by each cutting pattern (S.Qty), vary randomly. This means having to sort logs according to some attributes such as diameter class, species, length, taper, etc., which gives rise to the appearance of different subtypes (S.) in different quantities (S.Qty). This logs classification can be described in terms of different categories (S.) previously established. For example, it might be assumed that they are classified according to their characteristics and their suitability for being manufactured into certain product types, such as softwood lumber, hardwood lumber, pulp, and veneer (Beaudoin et al., 2007).

In this sector however, two aspects must be taken into account: age classes and fibre freshness (Beaudoin et al., 2007). When fresh fibre is used, common problems associated with log storage are checked, as is development due to drying and sap stains (even if sap stains do not change the structural integrity of the wood, it can severely affect its appearance, resulting in serious loss of value). Variation over age classes (S.Value) is reflected in both the processing cost and the quality of end products (any older fibre used can lower the expected profit margin of the end product). Degree of deterioration (S.State) may vary according to the season, tree species, the local environment and storage conditions, and may reduce values (S.Value).Thus in the wood sector, subtypes (S.) appear given the appearance of different qualities due to log 
characteristics, which are shown in different amounts (S.Qty) due to uncertainty in process yields, which also presents different values (S.Value) depending on the subtype characteristics that may vary over time, leading to deterioration in quality and value (S.State).

The reviewed papers on the wood sector are classified in Table 4. The most modelled "LHP Characteristic" is related to features of raw materials (S.), mainly due to their non-homogeneity (geometric characteristics, attributes, qualities) that cause randomness in process yield. This classification is based on the different categories established by the authors and leads to different subtypes (S.) in distinct quantities (S.Qty). Only one paper (Beaudoin et al., 2007) distinguishes subtype state (S.State) owing to the age classes and ages of harvested timber (deterioration of wood fibre). Although the existence of Subtype Value (S. Value) is possible due to the characteristics defined in this sector, it is not addressed by the authors.

In general, uncertainty in the wood sector is due to the non-homogeneous log characteristics, so process yields vary randomly. Another aspect that causes uncertainty is the age class, which can cause uncertainty in supply and process. Uncertainty can also exist due to price variation in the spot market and demand variation in commodity markets.

As shown in the "Uncertainty studied", all the reviewed papers, except one, analyse the process yield. However, Alem and Morabito (2012) deal with uncertainty in production costs and product demands, while Zanjani et al. (2010b) and Zanjani et al. (2013b) also deal with demand uncertainty. We highlight one paper (Beaudoin et al., 2007) which, apart from considering process yield, takes into account other sources of uncertainty such as standing inventories, stumpage fees, harvesting and transportation costs, storage and milling capacity and customer valuation levels. 
When comparing the modelled LHP characteristics with Uncertainty as considered by the authors, the "LHP inherent uncertainty" type that appears the most is quantities per subtype (S.Qty) in Process that are variable and not known with certainty due to process yield (in 6 of 7 papers). It is important to stress that one paper (Beaudoin et al., 2007) includes different LHP uncertainties and is the only one that deals with Subtype State (S. State). Besides considering quantities per subtype (S.Qty) in Process, Beaudoin et al. (2007) consider quantities per subtype (S.Qty) in Supply due to the classification of raw materials into subtypes, Subtype State (S. State) in Supply due to age classes and Subtype State in Process owing to wood fibre deterioration occurring during the process. Although "Uncertainty studied" on demand appears in some cases, none deals with it from a view point the LHP Inherent Uncertainty because finished goods are not differentiated by subtypes. Only one paper (Alem and Morabito, 2012) does not contemplate any LHP characteristic from an uncertain standpoint.

From the point of view "Uncertainty approach", all the papers adopt ScenarioBased Approach.

As regards the model block, the most widely used "Modelling approach" is Stochastic Programming (SP) (6 of 7), and only one paper suggests a Linear Programming (LP) model. None utilizes Fuzzy Programming (FP), Non-linear Programming (NLP), or Multi-objective programming (MOLP).

Almost all papers consider one objective related to the minimization of costs and only one contemplates the maximization of profits. For the "LHP Modelling", the analysed models define yields parameters and set constraints of inventory balance. Only one paper (Beaudoin et al., 2007) consider parameters that define the lower and upper ages by class of harvested timber, and constraints that represent conservation material flow. 


\section{Mining sector}

The planning and scheduling of mining extractions are a complicated process done in the presence of uncertainties such as the future commodity price and estimated ore grade (Johnson et al., 2010). In general terms, a mine system can be divided into three operations: mining, processing and refining. The raw materials extracted from many mines are sent to the processing units located in the mining area. Then processed materials are transported to the refining unit (Kumral, 2004). Several mines supply the raw materials for processing and ore properties and their quality varies depending on whether they come from different mines or from different seams (cuts). Raw ore from mines is classified according to its richness (S.) providing different amounts (S.Qty). For example, the quality of iron ore is assessed with regard to iron, silica, alumina, lime contents, among others. Afterwards, it is blended from several sources to obtain the desired level of quality required by the customer. Additionally, given that geological and structural ore body properties, such as seam thicknesses, depths, fault structures and physical characteristics, vary in each mine, ore prices and production costs can differ from one mine to another (S.Value). Moreover, content fluctuations may cause variations in the quality of the process or the finished product, and high concentration levels of some unwanted materials can lead to environmental pollution. Accordingly, during the production process, there are several stages of classification and can appear different subtypes (S.) with varying amounts (S.Qty) .Thus in this sector, subtypes (S.) appear because of existence of different ore qualities (in supply, in process and/or finished goods). This causes the appearance of different quantities or yields (S.Qty) which can also take different values (S.Value).

The reviewed papers relating to the mining sector are shown in Table 5. The most modelled LHP characteristic is quality (S.), mainly due to ore composition or ore 
grade. Items are classified according to different ranks or grades (S.) set by the authors, and different quantities appear per subtype (S.Qty). None distinguishes subtypes with distinct economic values (S.Value). Only one paper (Mitra, 2009) considers specific milling process parameters (grindability and sharpness) to classify ore, which leads to different subtype quantities (S.Qty).

As regards to uncertainty in the mining sector, Rico-Ramirez et al. (2009) classify market uncertainties as exogenous uncertainty and geological risk as endogenous uncertainty. According to Kamrad and Ernst (2001), market uncertainty in this environment is defined as either output price variability or random demand variability, while geological risk is captured by yield uncertainty that is defined as a random multiplier to output quantity. Martinez et al. (2009) explore the main sources of uncertainty that appear during mine planning. Uncertainty on future metal prices arises due to two main factors: lack of exact knowledge of those factors leading to metal supply and demand to increase/decrease; and the practices that producers or consumers carry out when faced with powerful speculative and political motives. Geology and ore distribution in a mineral deposit are estimated from the information deriving from exploration drilling samples. Since the information obtained from the samples is not representative of the entire ore deposit, the geology of the ore deposit is one of the most critical sources of technical uncertainty in a mining operation.

As shown in the "Uncertainty studied", all the reviewed papers analyse technical uncertainty, that is, the uncertainty that arises due to the composition or quality of the mineral. Only one paper (Chakraborty and Chandra, 2005) deals with the input cost of raw coal from a viewpoint uncertain, but it is known for each material.

The main "LHP inherent uncertainty type" that mostly appears is the quantities per subtype (S.Qty) in Supply that are variable and not known with certainty due to ore 
quality (in 7 of 9 papers). Of the remaining, one of them (Mitra, 2009) deals with LHP Inherent Uncertainty in the process that causes subtype quantities (S.Qty) to appear because specific milling process parameters (grindability and sharpness) are used to classify ore. The last one (Pendharkar, 1997) considers LHP Inherent Uncertainty on Demand also caused by subtype quantities (S.Qty) that appear due to the quality for a given attribute set by each market. Despite the number of subtypes (S.) appearing as an LHP characteristic, it is always considered constant and known with certainty, so it does not appear as LHP uncertainty. The "Uncertainty approach" mainly adopted are FuzzyBased Approach and Scenario-Based Approach. Only one paper mentions using Distribution-Based Approach.

From a point of view of "Modelling approach", different methods are used. The most employed one is Stochastic Programming (SP) (3 of 9). Two paper suggests a Linear Programming (LP) model, two others Fuzzy Programming (FP) and other two consider Non-linear Programming (NLP). It is noted that none uses Multi-objective programming (MOLP).

Papers mainly consider one objective related to the maximization of profit and one paper maximizes the throughput. Only one proposes the minimization of costs. Chakraborty and Chandra (2005) pose the optimization of the levels of raw coal of different grades to achieve desired specifications. In relation to the "LHP modelling", the models define parameters to reflect the quality due to ore composition or ore grade. In general constraints of material balance and/or product quality constraints with their grades maximum and minimum allowable are established.

\section{Ceramic sector}

Normally, ceramic pavings and coverings are placed and presented together, so their appearance needs to be homogeneous. However due to raw material heterogeneity 
(clay), some components (frits and enables) and uncontrollable factors in the process (temperature, humidity and pressure), units of the same model in the same lot which differ in aspect (quality), tone (colour) and gage (thickness) (S.). Different subtypes of one model should not be mixed to serve the same customer order (Alemany et al., 2013). The number of subtypes and their quantity can vary from one lot to another (S.Qty). Furthermore, ceramic tiles of different qualities are sold at different prices (S.Value).

As regards the modelled LHP characteristics in this sector (Table 6), Peidro et al. (2012) model only finished goods of first quality and scrap (S., S.Qty), and Mundi et al. (2013) model the appearance of homogeneous subsets of first quality (S., S.Qty) in lots, but none distinguishes subtypes with different economic values (S.Value).

Regarding uncertainty in the ceramic sector, and as shown in the "Uncertainty studied", Mundi et al. (2013) and Mundi et al. (2016) consider uncertainty in the appearance of homogeneous sublots. Peidro et al. (2012) do it for the uncertainty in the gross margin, idle time and backorder quantities. When considering the "LHP inherent uncertainty" Mundi et al. $(2013,2016)$ deal with LHP inherent uncertainty in process, because it analyses uncertainty in the number of subtypes that appear in the process and considers that quantities per subtype are variable and uncertain. Additionally, Mundi et al. (2016) model the demand in the master planning based on the number of customer orders with uncertain size that should be served with homogeneous sublots. Peidro et al. (2012) do not consider the LHP characteristic from a standpoint uncertain. Furthermore, Mundi et al. (2013) use Scenario-Based Approach and Peidro et al. (2012) and Mundi et al. (2016) employ the Fuzzy-Based Approach to model uncertainties.

As regards, the "Modelling approach", Mundi et al. (2013) formulates a Linear Programming (LP) model, whereas Peidro et al. (2012) and Mundi et al. (2016) use 
Fuzzy Programming (FP). Mundi et al. $(2013,2016)$ optimize the objective related to the maximization of gross margin or profit, respectively. Peidro et al. (2012) propose the maximization of the degree of satisfaction of three objectives: gross margin, backlogged demand and idle time of resources. The "LHP modelling" is included in the model by some parameters that express the percentage of first quality products and/or homogeneous products. Constraints of material balance and splitting of homogeneous sub-lots are set.

\section{Other Sectors}

LHP characteristics have been taken into account in other sectors like textile, chemicals, and so on, although we only found an unrepresentative sample. We also reviewed some papers in which the authors did not address any specific sector. We include in Table 7 all these papers examined.

In the paper of Kannegiesser et al. (2009) on the chemical industry (chemical commodities like polymers), commodities are the standard chemicals characterised by sales and supply volatility in volume and value. The characteristics of this SC are analogous to the petroleum sector in terms of the increasing and volatile prices of crude oil-dependent raw materials. Thus subtypes (S.) appear by the existence of different oil qualities due to their compositions or characteristics, giving place to different quantities or yields (S.Qty), which may have different values (S.Value). The LHP characteristics discussed in this work that appear are subtypes (S.) with different quantities per subtype (S.Qty) due to variable raw material consumption rates and different economic values (S.Value) as a result of the scaling prices of raw materials and demand. The paper considers uncertainty in sales prices for commodities and procurement prices for raw materials. Thus the LHP inherent uncertainty types that appear are: 1) Subtype Quantity in Supply and Subtype Value in Supply owing to variable raw material consumption 
rates with different economic values in supply and 2) Subtype Quantity in Demand and Subtype Value in Demand because of the quantity required per subtype and market is variable and not known with certainty, and the price of these subtypes on the market can be equal or differ, but it is not known with certainty. Finally, Kannegiesser et al. (2009) use a Linear Programming model (LP) and Scenario-Based Approach.

Rajaram and Karmarkar (2002) consider a refinery industry of wheat- and starch-based products, such as glucose, sorbitol, dextrose and gluten, which are utilized as components in the food processing, cosmetics, pharmaceuticals, textiles and specialty chemicals industries. As the production in these industries varies due to uncertainty in the yield of the chemical reactions employed in these processes, the characteristics of this SC are analogous to the petroleum sector already studied. Thus, subtypes (S.) appear by the different qualities of raw materials as result of their compositions or characteristics, giving place to different quantities or yields (S.Qty) which may take different values (S.Value). The LHP characteristic in the paper is the appearance of subtypes (S.) with different quantities per subtype (S.Qty) due to the inherent randomness in yield. The paper considers uncertainty in production yields, so LHP uncertainty occurs in Subtype Quantity in the process. From the modelling approach perspective, Rajaram and Karmarkar (2002) use Stochastic Programming (SP) and they adopt Distribution-Based Approach from a viewpoint Uncertainty modelling.

Karabuk (2008) deals with the textile sector. Yarn is manufactured by blending, combing, carding, roving and spinning natural and manmade fibres. After spinning, yarn is classified according to its thickness, which is measured as yarn count (S.). Therefore a final yarn product is identified by its blend type and count number (sku). This identification results in the appearance of different amounts per subtype (S.Qty). Despite this paper considers uncertainty on demand, no LHP characteristic is 
contemplated from a point of view uncertain. Stochastic Programming (SP) is chosen as the modelling approach and the Scenario-Based Approach is taken as the uncertainty modelling.

Wu et al. (2010) study the production and transportation in the film transistorliquid crystal display (TFT-LCD) industry. One of the characteristics of this industry is classification of assembly products and finished goods into quality grades (S., S.Qty), which may take different economic values (S.Value). The quality grades of TFT-LCD products result from production process yields. However, the paper examines uncertainty in price and demand of finished goods, so the LHP characteristic is not considered from a point of view uncertain. The modelling approach utilized is Stochastic Programming (SP), while the uncertainty modelling used is Scenario-Based Approach.

Rastogi et al. (2011) undertake their research in the semiconductor industry. The typical semiconductor supply network configuration consists of layers for wafer fab, sort, assembly, test and demand centres. There are two stages where classification is performed. These stages (sort and test) can lead to subtypes (S.) due to yield (S.Qty). The modelled LHP characteristics are yield of sort stage and yield of test stage (S., S.Qty). However, they consider only uncertainty on demand of finished goods, and no LHP characteristic is modelled uncertainly. The modelling approach used is Stochastic Programming (SP) and Scenario-Based Approach is chosen for uncertainty modelling. Rong and Lahdelma (2008) conduct their research in the steel industry. The raw materials employed in the steel industry come scrap metal. They are divided into several standard types and are classified into different subtypes based on chemical contents (S.), among others, which give rise to different amounts (S.Qty). The modelled "LHP characteristic" is raw materials composition and the "Uncertainty considered" occurs in 
raw materials composition and finished goods composition. Thus LHP uncertainty occurs in the number of subtypes in supply because they are not always the same materials and in the quantities by subtype in supply due to such quantities are variable and not known with certainty. Fuzzy Programming (FP) and the Fuzzy-Based Approach are chosen for uncertainty modelling.

Duenyas and Tsai (2000) consider a manufacturing system in which the quality of the end product is uncertain. Product is graded at several quality levels after production (S.), giving rise to different quantities (S.Qty). They assume stochastic demand per quality level, stochastic production time and random quality yields as "uncertainty considered". So LHP Inherent Uncertainty occurs in quantities by subtype on demand due to quantities per subtype are variable and not known with certainty. They use Stochastic Programming (SP) from a point of view the modelling approach, and the Distribution-Based Approach to model uncertainties from the Uncertainty modelling perspective.

Gupta and Grossmann (2011) present a generic model that contemplates endogenous uncertainty in yields. The endogenous uncertainty is represented by a parameter associated with the "source" of endogenous uncertainty. These parameters represent intrinsic properties of the source (S., S.Qty). Thus, these authors consider LHP Inherent Uncertainty in quantities per subtype in Process. They use Stochastic Programming (SP) as the modelling approach and the Scenario-Based Approach from the Uncertainty modelling perspective.

Wang and Zhang (2006) consider a generic agile SC by taking into account the internal quality and assembly quality in the model. This leads to the appearance of subtypes (S., S.Qty), but these authors consider that due date is uncertain, so the LHP characteristic is not contemplated from a standpoint uncertain. Furthermore in 
modelling approach terms, they employ Fuzzy Programming (FP) and adopt the FuzzyBased Approach as Uncertainty modelling.

Wazed et al. (2011) develop mathematical models for multiproduct and multistage production under quality and breakdown uncertainties. In manufacturing systems, a given proportion of products become defective due to poor production quality and material defects. Subsequently defective products are scrapped if they are not re-workable, or are not cost-effective to do so. This fact can lead to the appearance of subtypes (S.) that are classified into ranges to give rise to different amounts (S.Qty) during the process. Moreover, this paper uses Linear Programming (LP) as the modelling approach and the Scenario-Based Approach from the Uncertainty modelling perspective.

Osmani and Zhang (2013) consider a refinery of switchgrass to obtain biocombustible. As the production in these industries varies due to uncertainty in the yield of crops, thus, subtypes (S.) appear as a result of raw material yield. The LHP characteristic in the paper is the appearance of subtypes (S.) with different quantities per subtype (S.Qty) due to the randomness in yield of crops. The paper considers uncertainty on demand, sale price and switchgrass yield, so LHP uncertainty occurs in the supply. From the modelling approach perspective, Osmani and Zhang (2013) use Stochastic Programming (SP) and they adopt Scenario-Based Approach from a viewpoint Uncertainty modelling.

Finally, Xiao et al. (2012) propose a generic model for the supply-driven chain where quality disturbances (S.) occur in every SC node giving place to the occurrence of quantities per subtype (S.Qty). The imperfect quality along the supply-driven chain is modelled according to a function called quality disturbance, which is variable and not known. "Uncertainty considered" is an imperfect quality in every SC node (users, 
suppliers, manufacturers and distributors), so LHP Inherent Uncertainty occurs in quantities per subtype in supply, in process and on demand. From a viewpoint modelling approach, this paper uses a hybrid model (HYB) by combining Non-linear Programming and simulation. For uncertainty modelling, the authors employ the FuzzyBased Approach to model uncertainties.

Most papers consider one objective consisting in either the minimization of costs ( 5 of 12) or the maximization of profit ( 5 of 12). One paper maximizes the degree of satisfaction of the due date asked by the customer and another one proposes the minimization of impact of quality uncertainties in SC.

With the aim of achieving the LHP modelling, most models establish parameters defining the performance at some stage of the process, due to the quality or composition of the items. One model defines a linear recipe function for product-resource combination, other one establishes price ranges for each product-location combination and a model defines the quality disturbances of SC. In general, material balance or inventory balance constraints are established. Two models pose quality constraints and other model proposes constraints by means of transfer functions.

\section{Comparative analysis}

In this section, we first provide a global comparative analysis in order to assess which are the most LHP inherent uncertainty types modelled (Figure 5) and the most applied uncertainty and modelling approaches (Figure 6) for the production planning in industries characterised by LHP. This provides existing gaps for the LHP uncertainty modelling in general as a common research body. Then, we finish with a comparative analysis per sector in order to identify existing gaps in each specific industry and the possibility or not of transferring knowledge among them. 
Abstracting LHP uncertain characteristics of each industry has allowed to define the LHP inherent uncertainty types described in Figure 3. This classification constitutes the basis for our global comparative analysis which shows that all reviewed papers develop a model of production planning in an uncertain environment and all of them deal with some LHP characteristic in the model. But only the $70 \%$ consider some LHP characteristic uncertain, while the remaining 30\% deal with other parameters in an uncertain way. Figure 5 offers a classification of the reviewed papers according to the LHP uncertainty types defined by the authors. The most modelled LHP uncertainty aspect by far is Subtype Quantity (S.Qty) in 56 papers, but some authors deal with two types of uncertainty or more, which accounts for $81 \%$. The issues covered by the authors in this category are due to yields, quality issues, RM composition and FG specifications. Seven papers consider the Subtype State (S.State) (10\%), due to perishability, three papers deal with Subtype Value (S.Value) (4\%) by means of price, and three papers specifically consider number of Subtypes (S.) (4\%), owing to RM composition and qualities.

Therefore, we can state that the most LHP features addressed in an uncertainty context are quantities per subtype in raw materials and components (S.Qty in Supply) and quantities per subtype in intermediate products and finished goods (S.Qty in Process), while the remaining LHP inherent uncertainty types are very scarcely or not addressed under uncertainty. Therefore, this constitutes a gap identified in the existing literature.

The distribution of the reviewed papers according to modelling approach and uncertainty modelling is detailed in Figure 6. This proportion is similar considering only works with LHP uncertainty. The most widely employed modelling approach is Stochastic Programming (45\%) and the most used approach to model uncertainty is by 
far the Scenario-Based Approach (64\%). In fact, this is the combination of the most widely used modelling approaches (33 of 87), which represents $38 \%$. Stochastic Programming and the Scenario-Based Approach are used more for modelling purposes. This modelling purpose usually considers that one or more parameter, such as yields or qualities, are described by a set of discrete scenarios.

As shown, the MOLP approach has been used very little for LHP modelling $(6 \%)$. Yet other objectives relating to profits or costs in terms of minimization of undesirable stocks or dynamic subtype state, such as quality function loss, should be taken into account for certain situations. However, the Stochastic Programming (SP) and Scenario-Based approaches have two main drawbacks: they can be computationally inefficient and, very often, the distributions deriving from recorded past evidence are not always available or reliable (Mula et al., 2010b). Therefore, whenever statistical data are unreliable, or are not even available, stochastic models may not be the best choice (Wang and Shu, 2005). The Fuzzy Set Theory and the Possibility Theory may be an alternative, and are simpler and less data-demanding than the Probability Theory to deal with SC uncertainties (Dubois et al., 2003; Peidro et al., 2010). Fuzzy programming is proposed to handle these imprecise and/or unavailable data to help make decisions. However, very few authors consider this approach (10\%).

The Figure 7 focuses on the works that consider some LHP characteristic uncertain under a sector perspective. The second column in the figure shows the total number of revised papers by sector, meanwhile the third column shows only those papers modelling some LHP characteristic under uncertainty. For each sector, we compare the theoretical LHP characteristics that are uncertain in the reality (marked with an $\mathrm{X}$ in the corresponding column) against those considered by the authors in their work. The uncertainty and the modelling approach used are also reported. For clarity 
purposes, when the authors model the uncertainty in more than one LHP characteristic the specific combination is reported as a separate row. By means this representation it is possible to show the uncertain LHP characteristics common for different industries. We have shaded the areas in the "Uncertainty approach" and "Modelling approach" where no paper appears but the LHP uncertainty type exists. This shaded area allows easy to spot gaps in the state of the art per sector. Besides, for the existing gaps in a sector it is easy to find if there are other sectors with the same specific LHP characteristics that have been modeled and, in case, the uncertainty and modelling approaches used. This allows the transfer of knowledge among sectors.

We can see in Figure 7 that most works treat the subtype quantity (S.Qty) characteristic in an uncertain way. Surprisingly, although all the sectors present the Subtype (S.) uncertainty, only two papers in the ceramics and one in the steel sectors, deal with these type of uncertainty. Therefore, knowledge from these two sectors can be transferred to the others. As regards the S. State, only five papers in the agri-food sector consider this characteristic uncertain. Something similar occurs with the S. Value where only one paper in the also in the agri-food sector and another in the chemical industry appear. Therefore, it can be concluded that the Subtype, S. Value and S. State uncertainty type have been scarcely modelled, although they appear practically in all the industries. On the other hand, up to our knowledge there is no model that take into account the uncertainty in all the LHP types simultaneously for any sector. These means that no one represents exactly the reality because all the sector are affected at least by three types of LHP uncertainty. In short, it can be concluded that there are several gaps in the LHP uncertainty modelling, which means that field for further research exists. In next section the common elements among sectors and existing gaps are represented in a concise way by means a conceptual model. 


\section{Conceptual model}

Meredith (1993) defines a Conceptual Model as a set of concepts employed to represent or describe an event, object or process. It can be a description, a taxonomy or an inductive reflection. Our Conceptual Model (Figure 8) is based on an inductive reflection which integrates a number of different works on the same topic and summarizes the common elements. We pose a conceptual model from an exhaustive literature review which synthesizes existing research. This conceptual model arises from the theoretical foundations discussed in the literature review and brings together the aspects which have been considered so far when modelling the production planning in sectors with LHP in an uncertain environment. The model can be used by practitioners as a tool to identify common characteristics with other conducted researches. This allows to identify similarities between sectors and to transfer solutions from one sector to another. Thus, the purpose of the model is twofold. First, it summarizes the results of research by sector on modelling the uncertainty due to the lack of homogeneity in the product in the production planning, identifying and combining the most important aspects in a model which allows use it as a tool to identify the most advisable model. Second, researchers can use it as a framework to identify gaps in order to direct future research.

The conceptual model is described in Figure 8. We have classified each pair "uncertainty approach-modelling approach" used by the authors in their work, according to the sector and the LHP uncertainty addressed. The result of this classification structures the conceptual model into three blocks. The SECTOR block includes industries where some LHP uncertain characteristics are contemplated for planning purposes. These are: petroleum, agri-food, remanufacturing, wood, mining, ceramic, and other sectors like chemical, refinery and steel sectors. 
In the LHP UNCERTAINTY block, the LHP uncertain characteristics are grouped.

In the MODELLING block, we sort the approaches used by the papers analysed by sector and LHP uncertainty studied. That is, we link what modelling approach is used to pose each LHP characteristic and what approach is used to address their inherent uncertainty. We establish the relationship between sectors and "uncertainty approach-modelling approach" used by the authors in their work to model each LHP uncertainty. This enables to identify the most applied model to use as a pattern. On the other hand, we have identified existing gaps per sector where the uncertain LHP characteristic appears and no research exist.

Therefore, this conceptual framework can be used by practitioners of one sector to identify the approaches adopted to model some specific LHP characteristics under uncertainty in their own sector and contrast them with other sectors. In case no study exists in their own sector, they can consult work developed in other sectors. Finally, researchers can easily identify gaps in the literature. As we can observe, more research is necessary in the field of LHP uncertainty for planning purposes as regards the subtypes (S.), subtype value (S. Value) and subtype state (S. State). Besides, to explore different modelling approaches apart from Scenario-Stochastic Programming are also necessary.

\section{Conclusions and future research}

The management system becomes more difficult in the presence of LHP, increasing not only the information volume but also the uncertainty in the system. Dealing with LHP improperly can lead to very negative effects as regards stocks, customer service level and SC efficiency. Production Planning plays a crucial role in this task and becomes vital for accomplishing with customer requests in terms of ordered quantities, due dates 
and homogeneity specifications. Although LHP is present in several sectors, the incorporation of LHP uncertainty characteristics in Production planning is very scarce for some of them. These last could take profit from the know-how in other sectors if a common framework is available.

Along these lines, this work proposes an analysis framework which characterises the LHP inherent uncertainty according to three dimensions: environment (sector and LHP characteristic), uncertainty and modelling approaches. Then, research papers have been reviewed based on the previous analysis framework with the aim of knowing how LHP uncertainty is handled in Production planning models for different sectors. Conclusions drawn from this study assert that: (1) there are some sectors that consider LHP inherent uncertainty in the planning process, such as agri-food and remanufacturing, however, in other sectors very affected by LHP, the existing literature is scarce (mining, wood, ceramic) or inexistent (textile, jewel or leather); (2) the most considered LHP uncertainty aspect is the Subtype Quantity (S.Qty), mainly in supply whilst the other aspects (S., S.State, S.Value) are addressed very little or nothing; (3) the most widely modelling approach employed is Stochastic programming and the most used approach to model uncertainty is the Scenario-Based Approach. In fact this is the combination of the most widely used modelling approaches. Next, the paper offers a conceptualization of a pattern, based on the literature review, which synthesises the results of study for modelling the uncertainty due to the lack of homogeneity in the product in the production planning. The conceptual model identifies and ranks the most important aspects, to jointly model the LHP characteristics and their inherent uncertainty.

Therefore, it can be concluded that current production planning models do not provide complete adequate decision support for the uncertainty modelling of LHP 
characteristics. As already mentioned, production planning is one of the most important $\mathrm{SC}$ activities in the medium-short term, and it is one of the main inputs to the order promising process. Based on master plan quantities and committed customer orders, the so-called Available-To-Promise (ATP) quantities are derived. ATP quantities are then used for the quantity and due date setting of customer orders. The master plan should anticipate LHP features in order to provide with reliable information about future available homogeneous quantities for the order promising process, complying with customer homogeneity requirements.

Based on this review, we point out gaps in the literature and suggest future research: (1) there are very few works that pose models to address the LHP uncertainty on demand. Therefore, there is a need for optimization models and approaches of solution in this field; (2) there are very few works dealing with three of the four main aspects of relevance for planning purposes: the number of subtypes (S.), the subtype value (S.Value) and the subtype state (S.State); (3) very few authors consider fuzzy programming to handle imprecise and/or unavailable data to help make decisions. However, this approach may be a good alternative to the LHP uncertainty; (4) It is possible the identification of similarities among sectors being possible to transfer solutions from some sectors to other ones.

Existing research tends to oversimplify the real problem which can lead to shortterm conflict, when the planned amounts assumed homogeneous become real and the customer needs cannot be achieved due to discrepancies in the homogeneity requirements. This gap provides an opportunity to do new research as regards reference models, modelling and solution techniques to properly handle LHP inherent uncertainty types. This new research field will allow the development of more realistic models that can significantly improve the Production planning practice. 


\section{Acknowledgments}

This research was initiated within the framework of the project funded by the Spanish Ministry of Economy and Competitiveness (Ref. DPI2011-23597) entitled "Methods and models for operations planning and order management in supply chains characterised by uncertainty in production due to the lack of product uniformity" (PLANGES-FHP) already finished. After, the research was completed exclusively within the Project 691249, RUC-APS "Enhancing and implementing Knowledge based ICT solutions within high Risk and Uncertain Conditions for Agriculture Production Systems" funded by the EU under its funding scheme H2020-MSCARISE-2015.

We would like to thank you to the three anonymous reviewers and the editor all their suggestions, that have undoubtedly improved the original version of the paper.

\section{References}

Ahumada, O. \& Villalobos, J.R. 2009, "Application of planning models in the agri-food supply chain: A review", European Journal of Operational Research, vol. 196, no. 1, pp. 1-20.

Ahumada, O., Rene Villalobos, J. \& Nicholas Mason, A. 2012, "Tactical planning of the production and distribution of fresh agricultural products under uncertainty", Agricultural Systems, vol. 112, no. 0, pp. $17-26$.

Alarcón, F., Alemany, M.M.E., Lario, F. \& Oltra, R. 2011, "La falta de homogeneidad del producto (FHP) en las empresas cerámicas y su impacto en la reasignación del inventario" (Lack of homogeneity of the product (FHP) in the ceramics companies and its impact on the reassignment of the inventory), Boletín de la Sociedad Española de Cerámica y Vidrio, vol. 50, no. 1, pp. 49-58.

Albornoz, V. M., González-Araya, M., Gripe, M. C., \& Rodrıguez, S. V.2014. "A Mixed Integer Linear Program for Operational Planning in a Meat Packing Plant". http://www.researchgate.net/profile/Victor_Albornoz/publication/268687089_A_Mixed_Integer_Line ar_Program_for_Operational_Planning_in_a_Meat_Packing_Plant/links/547382bf0cf29afed60f55c7.p df, Online, accessed 15 January 2015.

Alem, D.J. \& Morabito, R. 2012, "Production planning in furniture settings via robust optimization", Computers \& Operations Research, vol. 39, no. 2, pp. 139-150.

Alemany, M., Lario, F., Ortiz, A. \& Gómez, F. 2013, "Available-To-Promise modeling for multi-plant manufacturing characterized by lack of homogeneity in the product: An illustration of a ceramic case", Applied Mathematical Modelling, vol. 37(5), pp. 3380-3398.

Alemany, M. M. E., Ortiz, A., Fuertes-Miquel, V. S., Bas, Á. O., \& Fuertes-Miquel, V. S. 2018. A decision support tool for the order promising process with product homogeneity requirements in hybrid MakeTo-Stock and Make-To-Order environments. Application to a ceramic tile company. Computers \& Industrial Engineering. 122, 219-234. 
Alfalla-Luque, R., Medina-Lopez, C., \& Dey, P. K. 2013. "Supply chain integration framework using literature review". Production Planning \& Control,24(8-9), 800-817.

Al-Othman, W.B.E., Lababidi, H.M.S., Alatiqi, I.M. \& Al-Shayji, K. 2008, "Supply chain optimization of petroleum organization under uncertainty in market demands and prices", European Journal of Operational Research, vol. 189, no. 3, pp. 822-840.

Al-Shammari, A. \& Ba-Shammakh, M.S. 2011, "Uncertainty Analysis for Refinery Production Planning", Industrial \& Engineering Chemistry Research, vol. 50, no. 11, pp. 7065-7072.

Amaro, A.C.S. \& Barbosa-Povoa, A.P.F.D. 2009, "The effect of uncertainty on the optimal closed-loop supply chain planning under different partnerships structure", Computers \& Chemical Engineering, vol. 33, no. 12 , pp. 2144-2158.

Aras, N., Boyaci, T. \& Verter, V. 2004, "The effect of categorizing returned products in remanufacturing", IIE Transactions (Institute of Industrial Engineers), vol. 36, no. 4, pp. 319-331.

Aydin, R., Kwong, C. K., Geda, M. W., \& Kremer, G. O. 2018. "Determining the optimal quantity and quality levels of used product returns for remanufacturing under multi-period and uncertain quality of returns". The International Journal of Advanced Manufacturing Technology, 94(9-12), 4401-4414.

Bakhrankova, K., Midthun, K. T., \& Uggen, K. T. 2014. "Stochastic optimization of operational production planning for fisheries". Fisheries Research, 157, 147-153.

Banasik, A., Kanellopoulos, A., Claassen, G. D. H., Bloemhof-Ruwaard, J. M., \& van der Vorst, J. G. 2017. "Closing loops in agricultural supply chains using multi-objective optimization: A case study of an industrial mushroom supply chain". International Journal of Production Economics, 183, 409-420.

Beaudoin, D., LeBel, L. \& Frayret, J. 2007, "Tactical supply chain planning in the forest products industry through optimization and scenario-based analysis", Canadian Journal of Forest Research-Revue Canadienne De RechercheForestiere, vol. 37, no. 1, pp. 128-140.

Begen, M.A. \& Puterman, M.L. 2003, "Development of a catch allocation tool design for production planning at JS McMillan fisheries", Infor, vol. 41, no. 3, pp. 235-244.

Benedito, E. \& Corominas, A. 2010, "Optimal manufacturing and remanufacturing capacities of systems with reverse logistics and deterministic uniform demand", Journal of Industrial Engineering and Management, vol. 3, no. 1, pp. 33-53.

Bertrand, J.W.M. \& Rutten, W.G.M.M. 1999, "Evaluation of three production planning procedures for the use of recipe flexibility", European Journal of Operational Research, vol. 115, no. 1, pp. 179-194.

Björheden, R. 2005, "Raw Material Procurement in Sawmills' Business Level Strategy - A Contingency Perspective", International Journal of Forest Engineering, vol. 16, no. 2.

Bohle, C., Maturana, S. \& Vera, J. 2010, "A robust optimization approach to wine grape harvesting scheduling", European Journal of Operational Research, vol. 200, no. 1, pp. 245-252. 
Cai, X., Lai, M., Li, X., Li, Y., \& Wu, X. 2014. "Optimal acquisition and production policy in a hybrid manufacturing/remanufacturing system with core acquisition at different quality levels". European Journal of Operational Research,233(2), 374-382.

Carneiro, M.C., Ribas, G.P. \& Hamacher, S. 2010, "Risk Management in the Oil Supply Chain: A CVaR Approach", Industrial \& Engineering Chemistry Research, vol. 49, no. 7, pp. 3286-3294.

Chakraborty, M. \& Chandra, M.K. 2005, "Multicriteria decision making for optimal blending for beneficiation of coal: a fuzzy programming approach", Omega-International Journal of Management Science, vol. 33, no. 5, pp. 413-418.

Chunpeng, L., \& Gang, R. 2009, "A Strategy for the Integration of Production Planning and Scheduling in Refineries under Uncertainty", Chinese Journal of Chemical Engineering, vol. 17, no. 1, pp. 113-127.

Davoli, G., Gallo, S.A., Collins, M.W. \& Melloni, R. 2010, "A stochastic simulation approach for production scheduling and investment planning in the tile industry", International Journal of Engineering, Science and Technology, vol. 2, no. 9.

Denizel, M., Ferguson, M. \& Souza, G.".C. 2010, "Multiperiod Remanufacturing Planning With Uncertain Quality of Inputs", IEEE Transactions on Engineering Management, vol. 57, no. 3, pp. 394-404.

Dong, M., Lu, S. \& Han, S. 2011, "Production planning for hybrid remanufacturing and manufacturing system with component recovery", Lecture Notes in Electrical Engineering, vol. 134 LNEE, pp. 511518.

Dubois, D., Fargier, H. \& Fortemps, P. 2003, "Fuzzy scheduling: Modelling flexible constraints vs. coping with incomplete knowledge", European Journal of Operational Research, vol. 147, no. 2, pp. 231-252.

Duenyas, I., \& Tsai, C. Y., I. 2000, "Control of a manufacturing system with random product yield and downward substitutability", IIE Transactions, vol. 32, no. 9, pp. 785-795.

Entrup, M.L. 2005, "Advanced planning in fresh food industries [electronic resource]: integrating shelf life into production planning", Springer.

French, M. L., \& LaForge, R. L. 2006, "Closed-loop supply chains in process industries: An empirical study of producer re-use issues". Journal of Operations Management, 24(3), 271-286.

Gallo, M., Grisi, R., Guizzi, G. \& Romano, E. 2009, "A comparison of production policies in remanufacturing systems", Proceedings of the 8th WSEAS International Conference on System Science and Simulation in Engineering, ICOSSSE '09, pp. 334.

Goodfellow, R., \& Dimitrakopoulos, R. 2017. "Simultaneous stochastic optimization of mining complexes and mineral value chains". Mathematical Geosciences, 49(3), 341-360.

Graves, S.C. 2011, "Uncertainty and production planning", Planning Production and Inventories in the Extended Enterprise, , pp. 83-101.

Grillo, H., Alemany, M. M. E., Ortiz, A., \& Fuertes-Miquel, V. S. 2017. Mathematical modelling of the order-promising process for fruit supply chains considering the perishability and subtypes of products. Applied Mathematical Modelling, 49, 255-278. 
Guan, Z. \& Philpott, A.B. 2011, "A multistage stochastic programming model for the New Zealand dairy industry", International Journal of Production Economics, vol. 134, no. 2, pp. 289-299.

Guide, V.D.R. 2000, "Production planning and control for remanufacturing: industry practice and research needs", Journal of Operations Management, vol. 18, no. 4, pp. 467-483.

Gupta, V. \& Grossmann, I.E. 2011, "Solution strategies for multistage stochastic programming with endogenous uncertainties", Computers \& Chemical Engineering, vol. 35, no. 11, pp. 2235-2247.

Gupta, S. \& Nan, Z. 2006, "Multiperiod planning of refinery operations under market uncertainty", AIChE Annual Meeting, Conference Proceedings.

Heckmann, I., Comes, T., \& Nickel, S. 2015. "A critical review on supply chain risk-Definition, measure and modeling". Omega, 52, 119-132.

Heydari, J., \& Ghasemi, M. 2018. "A revenue sharing contract for reverse supply chain coordination under stochastic quality of returned products and uncertain remanufacturing capacity". Journal of Cleaner Production.

Hovelaque, V., Duvaleix-Treguer, S. \& Cordier, J. 2009, "Effects of constrained supply and price contracts on agricultural cooperatives", European Journal of Operational Research, vol. 199, no. 3, pp. 769-780.

Hsieh, S. \& Chiang, C.C. 2001, "Manufacturing-to-sale planning model for fuel oil production", International Journal of Advanced Manufacturing Technology, vol. 18, no. 4, pp. 303-311.

Igarashi, M., de Boer, L., \& Fet, A. M. 2013. "What is required for greener supplier selection? A literature review and conceptual model development". Journal of Purchasing and Supply Management, 19(4), 247-263.

Jamshidi, M., \& Osanloo, M. 2018. "Reliability analysis of production schedule in multi-element deposits under grade-tonnage uncertainty with multi-destinations for the run of mine material". International Journal of Mining Science and Technology.

Jindal, A., \& Sangwan, K. S. 2017. "Multi-objective fuzzy mathematical modelling of closed-loop supply chain considering economical and environmental factors". Annals of Operations Research, 257(1-2), 95-120.

Jin, X., Hu, S. J., Ni, J., \& Xiao, G. 2013. "Assembly strategies for remanufacturing systems with variable quality returns". Automation Science and Engineering, IEEE Transactions on, 10(1), 76-85.

Johnson, P., Evatt, G., Duck, P. \& Howell, S. 2010, "The derivation and impact of an optimal cut-off grade regime upon mine valuations", Proceedings of the World Congress on Engineering 2010 Vol I.

Junior, M.L. \& Filho, M.G. 2012, "Production planning and control for remanufacturing: literature review and analysis", Production Planning \& Control, vol. 23, no. 6, pp. 419-435.

Kamrad, B. \& Ernst, R. 2001, "An economic model for evaluating mining and manufacturing ventures with output yield uncertainty", Operations research, vol. 49, no. 5, pp. 690-699. 
Kannegiesser, M., Guenther, H.-., van Beek, P., Grunow, M. \& Habla, C. 2009, "Value chain management for commodities: a case study from the chemical industry", Or Spectrum, vol. 31, no. 1, pp. 63-93.

Karabuk, S. 2008, "Production planning under uncertainty in textile manufacturing", Journal of the Operational Research Society, vol. 59, no. 4, pp. 510-520.

Khor, C.S. 2007, "A hybrid of stochastic programming approaches with economic and operational risk management for petroleum refinery planning under uncertainty", Masters Abstracts International.

Khor, C., Elkamel, A. \& Douglas, P. 2008, "Stochastic refinery planning with risk management", Petroleum Science and Technology, vol. 26, no. 14, pp. 1726-1740.

Kumral, M. 2004, "Genetic algorithms for optimization of a mine system under uncertainty", Production Planning \& Control, vol. 15, no. 1, pp. 34-41.

Lalmazloumian, M., \& Wong, K. Y. 2012, "A review of modelling approaches for supply chain planning under uncertainty", Service Systems and Service Management (ICSSSM), 2012 9th International Conference on, pp. 197.

Leiras, A., Ribas, G., Hamacher, S., \& Elkamel, A. 2013. "Tactical and Operational Planning of Multirefinery Networks under Uncertainty: An Iterative Integration Approach". Industrial \& Engineering Chemistry Research, 52(25), 8507-8517.

Liao, H., Deng, Q., \& Wang, Y. 2017. "Optimal acquisition and production policy for end-of-life engineering machinery recovering in a joint manufacturing/remanufacturing system under uncertainties in procurement and demand". Sustainability, 9(3), 338.

Loomba, A.P.S. \& Nakashima, K. 2012, "Enhancing value in reverse supply chains by sorting before product recovery", Production Planning \& Control, vol. 23, no. 2, pp. 205-215.

Macedo, P. B., Alem, D., Santos, M., Junior, M. L., \& Moreno, A. 2016. "Hybrid manufacturing and remanufacturing lot-sizing problem with stochastic demand, return, and setup costs". The International Journal of Advanced Manufacturing Technology, 82(5-8), 1241-1257.

Martinez, L. 2009, "Why accounting for uncertainty and risk can improve final decision-making in strategic open pit mine evaluation", Project Evaluation Conference, Melbourne, pp. 1.

Matamoros, M. E. V., \& Dimitrakopoulos, R. 2016. "Stochastic short-term mine production schedule accounting for fleet allocation, operational considerations and blending restrictions". European journal of operational research, 255(3), 911-921.

Meredith, J. 1993. "Theory building through conceptual methods". International Journal of Operations \& Production Management, 13(5), 3-11.

Miller, W.A., Leung, L.C., Azhar, T.M. \& Sargent, S. 1997, "Fuzzy production planning model for fresh tomato packing", International Journal of Production Economics, vol. 53, no. 3, pp. 227-238.

Mitra, K. 2009, "Multiobjective optimization of an industrial grinding operation under uncertainty", Chemical Engineering Science, vol. 64, no. 23, pp. 5043-5056. 
Moghaddam, K. S. 2015. "Fuzzy multi-objective model for supplier selection and order allocation in reverse logistics systems under supply and demand uncertainty". Expert Systems with Applications, 42(15-16), 6237-6254.

Mula, J., Peidro, D., Díaz-Madroñero, M. \& Vicens, E. 2010a, "Mathematical programming models for supply chain production and transport planning", European Journal of Operational Research, vol. 204, no. 3 , pp. $377-390$.

Mula, J., Peidro, D. \& Poler, R. 2010b, "The effectiveness of a fuzzy mathematical programming approach for supply chain production planning with fuzzy demand", International Journal of Production Economics, vol. 128, no. 1, pp. 136-143.

Mundi, I., Alemany, M., Boza, A. \& Poler, R. 2013, "A Model-Driven Decision Support System for the Master Planning of Ceramic Supply Chains with Non-uniformity of Finished Goods", Studies in Informatics and Control, vol. 22, no. 2, pp. 153-162.

Mundi, M. I., Alemany, M. M. E., Poler, R., \& Fuertes-Miquel, V. S. 2016. "Fuzzy sets to model master production effectively in Make to Stock companies with Lack of Homogeneity in the Product". Fuzzy Sets and Systems, 293, 95-112.

Munhoz, J. R., \& Morabito, R. 2014. "Optimization approaches to support decision making in the production planning of a citrus company: A Brazilian case study". Computers and Electronics in Agriculture, 107, 45-57.

Olivetti, E.A., Gaustad, G.G., Field, F.R. \& Kirchain, R.E. 2011, "Increasing Secondary and Renewable Material Use: A Chance Constrained Modeling Approach To Manage Feedstock Quality Variation", Environmental science \& technology, vol. 45, no. 9, pp. 4118-4126.

Osmani, A., \& Zhang, J. 2013. "Stochastic optimization of a multi-feedstock lignocellulosic-based bioethanol supply chain under multiple uncertainties". Energy, 59, 157-172.

Paksoy, T., Pehlivan, N.Y. \& Ozceylan, E. 2012, "Application of fuzzy optimization to a supply chain network design: A case study of an edible vegetable oils manufacturer", Applied Mathematical Modelling, vol. 36, no. 6, pp. 2762-2776.

Pauls-Worm, K. G., Hendrix, E. M., Haijema, R., \& van der Vorst, J. G. 2014. "An MILP approximation for ordering perishable products with non-stationary demand and service level constraints". International Journal of Production Economics, 157, 133-146.

Peidro, D., Mula, J., Jiménez, M. \& del Mar Botella, M. 2010, "A fuzzy linear programming based approach for tactical supply chain planning in an uncertainty environment", European Journal of Operational Research, vol. 205, no. 1, pp. 65-80.

Peidro, D., Mula, J., Poler, R. \& Lario, F.C. 2009, "Quantitative models for supply chain planning under uncertainty: a review", The International Journal of Advanced Manufacturing Technology, vol. 43, no. 3, pp. 400-420. 
Peidro, D., Mula, J., Alemany, M.M.E. \& Lario, F. 2012, "Fuzzy multi-objective optimisation for master planning in a ceramic supply chain", International Journal of Production Research, vol. 50, no. 11, pp. 3011-3020.

Pendharkar, P. C. 2013. "Scatter search based interactive multi-criteria optimization of fuzzy objectives for coal production planning". Engineering Applications of Artificial Intelligence, 26(5), 1503-1511.

Pendharkar, P.C. 1997, "A fuzzy linear programming model for production planning in coal mines", Computers \& Operations Research, vol. 24, no. 12, pp. 1141.

Phuc, P. N. K., Yu, V. F., \& Chou, S. Y. 2013. "Optimizing the Fuzzy Closed-Loop Supply Chain for Electrical and Electronic Equipments". International Journal of Fuzzy Systems, 15(1), 9-21.

Pitty, S.S., Li, W., Adhitya, A., Srinivasan, R. \& Karimi, I.A. 2008, "Decision support for integrated refinery supply chains Part 1. Dynamic simulation", Computers \& Chemical Engineering, vol. 32, no. 11, pp. 2767-2786.

Poles, R. \& Cheong, F. 2009, "A system dynamics model for reducing uncertainty in remanufacturing systems", PACIS 2009 - 13th Pacific Asia Conference on Information Systems: IT Services in a Global Environment.

Pongsakdi, A., Rangsunvigit, P., Siemanond, K. \& Bagajewicz, M.J. 2006, "Financial risk management in the planning of refinery operations", International Journal of Production Economics, vol. 103, no. 1, pp. 64-86.

Radulescu, M., Zbaganu, G. \& Radulescu, C.Z. 2008, "Crop Planning in the Presence of Production Quotas (Invited Paper)", Computer Modeling and Simulation, 2008.UKSIM 2008. Tenth International Conference on, pp. 549.

Rajaram, K. \& Karmarkar, U.S. 2002, "Product cycling with uncertain yields: Analysis and application to the process industry", Operations research, vol. 50, no. 4, pp. 680-691.

Ramasesh, R. V., \& Browning, T. R. 2014, "A conceptual framework for tackling knowable unknown unknowns in project management". Journal of Operations Management, 32(4), 190-204.

Randhawa, S.U. \& Bjarnason, E.T. 1995, "A decision aid for coordinating fishing and fish processing", European Journal of Operational Research, vol. 81, no. 1, pp. 62-75.

Rastogi, A.P., Fowler, J.W., Carlyle, W.M., Araz, O.M., Maltz, A. \& Bueke, B. 2011, "Supply network capacity planning for semiconductor manufacturing with uncertain demand and correlation in demand considerations", International Journal of Production Economics, vol. 134, no. 2, pp. 322-332.

Ravi, V. \& Reddy, P.J. 1998, "Fuzzy linear fractional goal programming applied to refinery operations planning", Fuzzy Sets and Systems, vol. 96, no. 2, pp. 173-182.

Ribas, G.P., Hamacher, S. \& Street, A. 2010, "Optimization under uncertainty of the integrated oil supply chain using stochastic and robust programming", International Transactions in Operational Research, vol. 17, no. 6, pp. 777-796. 
Rico-Ramirez, V., Grossmann, I.E., Tarhan, B., Hernandez-Castro, S. \& Segovia-Hernandez, J.G. 2009, "An Approach to the Representation of Gradual Uncertainty Resolution in Stochastic Multiperiod Planning", 19th European Symposium on Computer Aided Process Engineering, vol. 26, pp. 713-718.

Rocco, C. D., \& Morabito, R. (2016). "Production and logistics planning in the tomato processing industry: A conceptual scheme and mathematical model". Computers and Electronics in Agriculture, 127, 763774.

Roitsch, M. \& Meyr, H. 2008, "Oil Industry" in Supply Chain Management and Advanced Planning Springer, , pp. 399-414.

Rong, A. \& Lahdelma, R. 2008, "Fuzzy chance constrained linear programming model for optimizing the scrap charge in steel production", European Journal of Operational Research, vol. 186, no. 3, pp. 953964.

Sel, Ç., Bilgen, B., \& Bloemhof-Ruwaard, J. 2017. "Planning and scheduling of the make-and-pack dairy production under lifetime uncertainty". Applied Mathematical Modelling, 51, 129-144.

Sel, Ç., Soysal, M., \& Çimen, M. 2017. "A green model for the catering industry under demand uncertainty". Journal of Cleaner Production, 167, 459-472.

Schutz, P. \& Tomasgard, A. 2011, "The impact of flexibility on operational supply chain planning", International Journal of Production Economics, vol. 134, no. 2, pp. 300-311.

Seth, N., Deshmukh, S. G., \& Vrat, P. 2006. "A conceptual model for quality of service in the supply chain". International Journal of Physical Distribution \& Logistics Management, 36(7), 547-575.

Seuring, S., \& Müller, M. 2008. "From a literature review to a conceptual framework for sustainable supply chain management". Journal of cleaner production, 16(15), 1699-1710.

Shi, J., Liu, Z., Zhu, C. \& Zhang, Y. 2011, "Optimal production planning for a closed loop system with quality uncertainty of used product", Proceedings - 2011 4th International Conference on Information Management, Innovation Management and Industrial Engineering, ICIII 2011, pp. 394.

Su, T. S., \& Lin, Y. F. 2015. "Fuzzy multi-objective procurement/production planning decision problems for recoverable manufacturing systems". Journal of Manufacturing Systems, 37, 396-408.

Tan, B. \& Çömden, N. 2012, "Agricultural planning of annual plants under demand, maturation, harvest, and yield risk", European Journal of Operational Research, vol. 220, no. 2, pp. 539-549.

Tarhan, B., Grossmann, I.E. \& Goel, V. 2011, "Computational strategies for non-convex multistage MINLP models with decision-dependent uncertainty and gradual uncertainty resolution", Annals of Operations Research, , pp. 1-26.

Tong, K., Feng, Y. \& Rong, G. 2012, "Planning under Demand and Yield Uncertainties in an Oil Supply Chain", Industrial \& Engineering Chemistry Research, vol. 51, no. 2, pp. 819-839.

Van der Vorst, Jack GAJ \& Beulens, A.J. 2002, "Identifying sources of uncertainty to generate supply chain redesign strategies", International Journal of Physical Distribution \& Logistics Management, vol. 32, no. 6 , pp. 409-430. 
Van Donk, D.P., Akkerman, R. \& Van der Vaart, T. 2008, "Opportunities and realities of supply chain integration: the case of food manufacturers", British Food Journal, vol. 110, no. 2, pp. 218-235.

Van Wezel, W., Van Donk, D. P., \& Gaalman, G. 2006, "The planning flexibility bottleneck in food processing industries". Journal of Operations Management, 24(3), 287-300.

Vorst, Jacobus Gerardus Adrianus Johannes van der 2000, "Effective food supply chains: generating, modelling and evaluating supply chain scenarios". Doctoral Thesis, Wageningen Universiteit.

Wang, W. \& Zhang, Y. 2006, "An approach of production planning for agile supply chain quality management", American Control Conference, 2006IEEE, , pp. 2545.

Wang, H. \& Zheng, K. 2010, "An optimal run-mode scheduling for oil refinery production-a case study on Taiwan CPC Corporation", Production Planning \& Control, vol. 21, no. 3, pp. 301-318.

Wang, J. \& Shu, Y. 2005, "Fuzzy decision modeling for supply chain management", Fuzzy Sets and Systems, vol. 150, no. 1, pp. 107-127.

Wazed, M.A., Ahmed, S. \& Nukman, Y.B. 2011, "Mathematical models for process commonality under quality and resources breakdown in multistage production", Journal of Zhejiang University: Science $A$, vol. 12 , no. 11 , pp. $837-848$.

Wu, C.-., Lin, J.T. \& Wu, H.-. 2010, "Robust production and transportation planning in thin film transistorliquid crystal display (TFT-LCD) industry under demand and price uncertainties", International Journal of Production Research, vol. 48, no. 20, pp. 6037-6060.

Xiao, R., Cai, Z. \& Zhang, X. 2012, "A production optimization model of supply-driven chain with quality uncertainty", Journal of Systems Science and Systems Engineering, vol. 21, no. 2, pp. 144-160.

Yazıcı, E., Büyüközkan, G., \& Baskak, M. 2016. "A New Extended MILP MRP Approach to Production Planning and Its Application in the Jewelry Industry". Mathematical Problems in Engineering, vol. 2016.

Zanjani, M.K., Ait-Kadi, D., \& Nourelfath, M. 2013a. "A stochastic programming approach for sawmill production planning". International Journal of Mathematics in Operational Research, 5(1), 1-18.

Zanjani, M. K., Ait-Kadi, D., \& Nourelfath, M. 2013b. "An accelerated scenario updating heuristic for stochastic production planning with set-up constraints in sawmills". International Journal of Production Research, 51(4), 993-1005.

Zanjani, M.K., Nourelfath, M. \& Ait-Kadi, D. 2011, "Production planning with uncertainty in the quality of raw materials: a case in sawmills", Journal of the Operational Research Society, vol. 62, no. 7, pp. 1334-1343.

Zanjani, M.K., Ait-Kadi, D. \& Nourelfath, M. 2010a, "Robust production planning in a manufacturing environment with random yield: A case in sawmill production planning", European Journal of Operational Research, vol. 201, no. 3, pp. 882-891. 
Zanjani, M.K., Nourelfath, M. \& Ait-Kadi, D. 2010b, "A multi-stage stochastic programming approach for production planning with uncertainty in the quality of raw materials and demand", International Journal of Production Research, vol. 48, no. 16, pp. 4701-4723.

Zeballos, L.J., Gomes, M.I., Barbosa-Povoa, A.P. \& Novais, A.Q. 2012, "Addressing the uncertain quality and quantity of returns in closed-loop supply chains", Computers \& Chemical Engineering, vol. 47, no. 0, pp. 237-247.

Zhang, J., Wen, Y. \& Xu, Q. 2012, "Simultaneous optimization of crude oil blending and purchase planning with delivery uncertainty consideration", Industrial and Engineering Chemistry Research, vol. 51, no. 25, pp. 8453-8464.

Zimberg, B. \& Testuri, C.E. 2006, "Stochastic analysis of crude oil procurement and processing under uncertain demand for bunker fuel oil", International Transactions in Operational Research, vol. 13, no. 5, pp. 387-402. 


\section{FIGURES}

Figure 1. Distribution of the papers reviewed by year of publication.

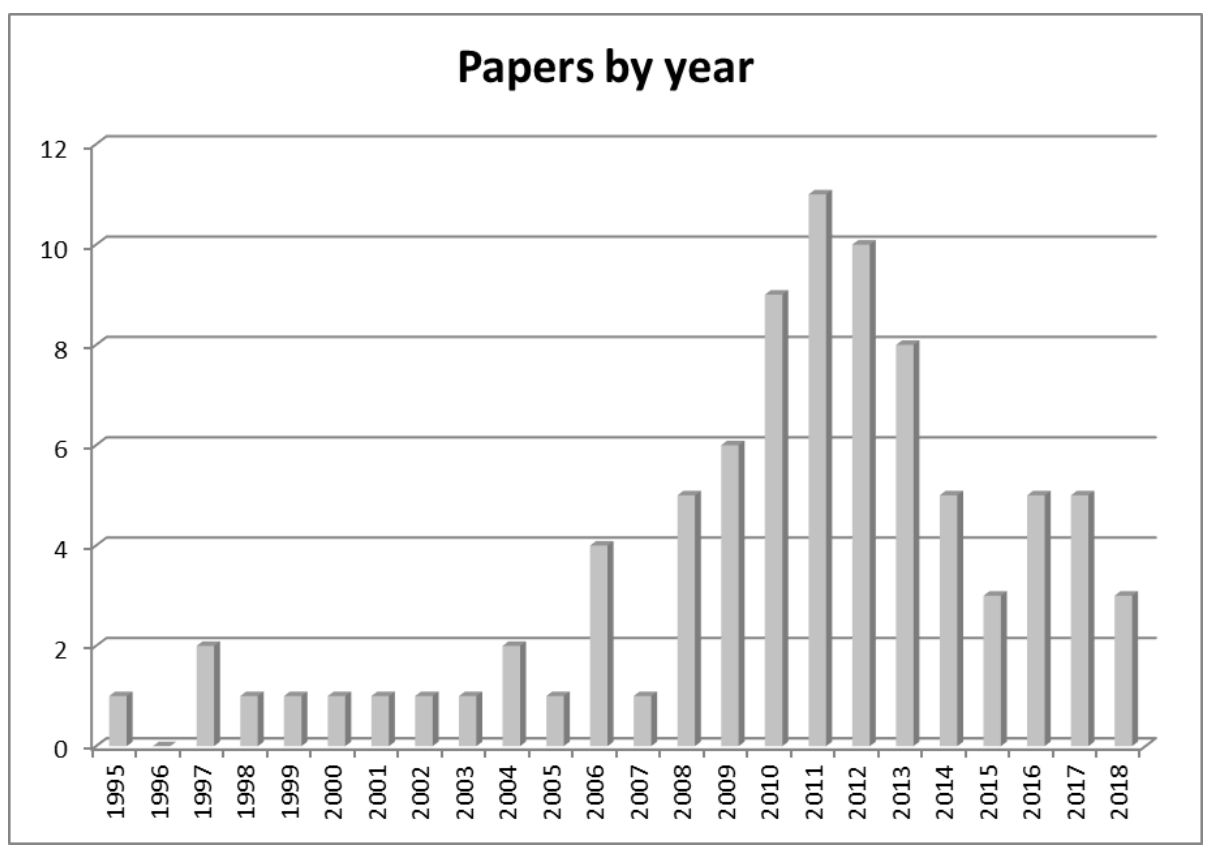

Figure 2. Analysis Framework for the literature review of the SC Production Planning models considering LHP inherent uncertainty types

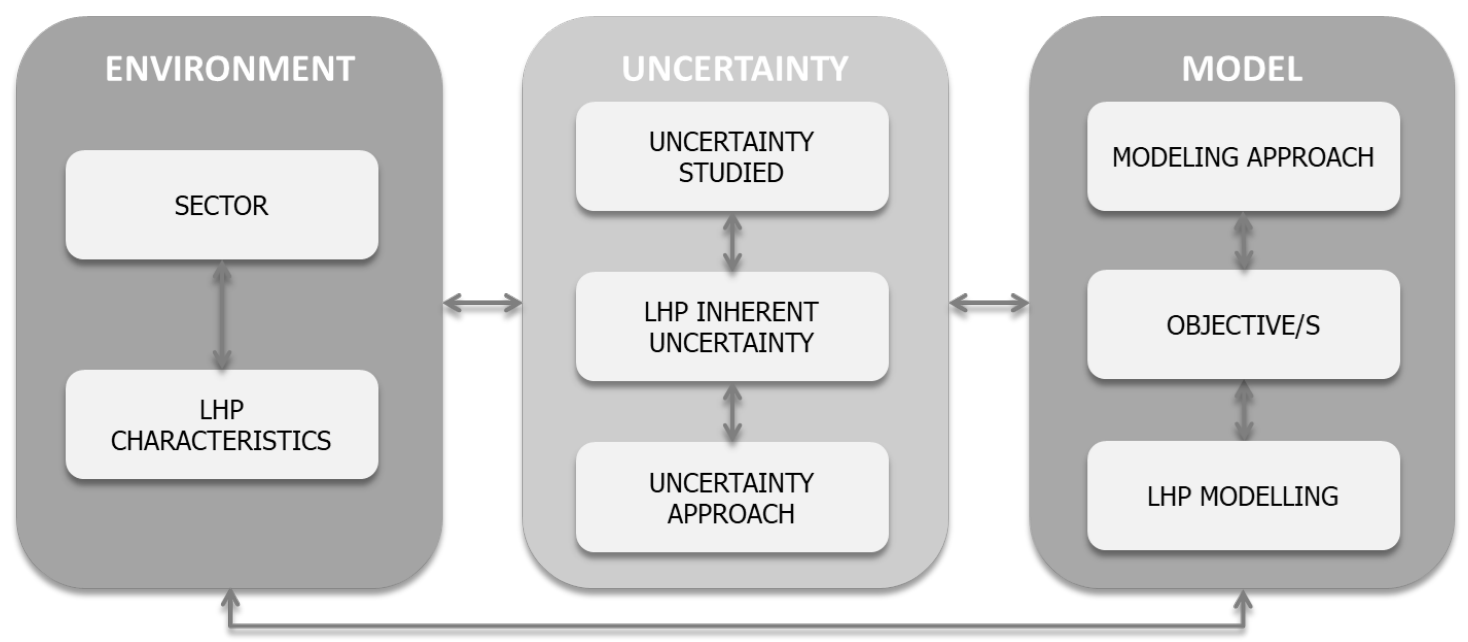


Figure 3. LHP inherent uncertainty types

\begin{tabular}{|c|c|c|c|}
\hline $\begin{array}{l}\text { Uncertainty Types/ } \\
\text { LHP Aspects }\end{array}$ & Supply & Process & Demand \\
\hline Subtypes (S.) & $\begin{array}{l}\text { Uncertainty number of subtypes in supplied raw } \\
\text { materials or components (LHRM) in a specific } \\
\text { lot or among lots }\end{array}$ & $\begin{array}{l}\text { Uncertainty number of subtypes in intermediate (LHI) } \\
\text { or finished goods (LHP) }\end{array}$ & $\begin{array}{l}\text { Uncertainty in the subtypes (LHP) required per } \\
\text { customers/markets in their orders }\end{array}$ \\
\hline $\begin{array}{l}\text { Subtype quantity } \\
\text { (S.Qty) }\end{array}$ & $\begin{array}{l}\text { Quantities per subtype of LHRM (in the same lot } \\
\text { or among lots) is variable and not known with } \\
\text { certainty }\end{array}$ & $\begin{array}{l}\text { Quantities per subtype of LHI or LHP (in the same } \\
\text { lot or among lots) is variable and not known with } \\
\text { certainty }\end{array}$ & $\begin{array}{l}\text { Quantity required for each subtype (LHP) and } \\
\text { customer/market variable and not known with } \\
\text { certainty. }\end{array}$ \\
\hline $\begin{array}{l}\text { Subtype value } \\
\text { (S.Value) }\end{array}$ & $\begin{array}{l}\text { The value (cost) of supplied subtypes can be } \\
\text { equal or different but it is not known with } \\
\text { certainty (cost depends on the availability and } \\
\text { demand of LHRM subtypes) }\end{array}$ & $\begin{array}{l}\text { The value (cost) of produced LHI subtypes can be } \\
\text { equal or different but it is not known with certainty } \\
\text { (cost depends on the LHP subtypes demand, } \\
\text { process (storage conditions) or the final availability of } \\
\text { subtypes) }\end{array}$ & $\begin{array}{l}\text { The value (price) of produced subtypes (LHP) } \\
\text { in the market can be equal or different but it is } \\
\text { not known with certainty. }\end{array}$ \\
\hline $\begin{array}{l}\text { Subtype state } \\
\text { (S.State) }\end{array}$ & $\begin{array}{l}\text { The state of the subtype (LHRM) is dynamic and } \\
\text { its evolution is not known with certainty } \\
\text { (perishability, obsolescence) }\end{array}$ & $\begin{array}{l}\text { The state of the subtype (LHI or LHP) is dynamic } \\
\text { and its evolution is not known with certainty } \\
\text { (perishability, obsolescence) }\end{array}$ & $\begin{array}{l}\text { The state of the subtype (LHP) is dynamic and } \\
\text { its evolution is not known with certainty } \\
\text { (perishability, obsolescence) }\end{array}$ \\
\hline
\end{tabular}

Figure 4. Modelling approach codes

\begin{tabular}{ll}
\hline Modelling approach & Code \\
\hline Linear programming & LP \\
Non-linear programming & NLP \\
Multi-objective programming & MOLP \\
Fuzzy programming & FP \\
Stochastic programming & SP \\
Hybrid models & HYB \\
\hline
\end{tabular}


Figure 5. Classification of the reviewed papers according to LHP inherent uncertainty types.

\begin{tabular}{|c|c|c|c|}
\hline $\begin{array}{l}\text { Uncertainty } \\
\text { Types/ LHP } \\
\text { Uncertainty } \\
\text { Aspects }\end{array}$ & Supply & Process & Demand \\
\hline $\begin{array}{l}\text { Subtypes } \\
\text { (S.) }\end{array}$ & Rong et al (2008) & $\begin{array}{l}\text { Mundi et al (2013) } \\
\text { Mundi et al (2016) }\end{array}$ & \\
\hline $\begin{array}{l}\text { Subtype } \\
\text { quantity } \\
\text { (S.Qty) }\end{array}$ & $\begin{array}{l}\text { Ahumada et al (2012) } \\
\text { Tan et al (2012) } \\
\text { Bertrand et al (1999) } \\
\text { Randhawa et al (1995) } \\
\text { Rico-Ramirez et al (2009) } \\
\text { Chakraborty et al (2005) } \\
\text { Kumral (2004) } \\
\text { Carneiro et al (2010) } \\
\text { Luo et al (2009) } \\
\text { Zimberg et al (2006) } \\
\text { Aras et al (2004) } \\
\text { Benedito et al (2010) } \\
\text { Denizel et al (2010) } \\
\text { Dong et al (2011) } \\
\text { Shi et al (2011) } \\
\text { Olivetti et al (2011) } \\
\text { Zeballos et al (2012) } \\
\text { Rong et al (2008) } \\
\text { Xiao et al (2012) } \\
\text { Kannegiesser et al (2009) } \\
\text { Beaudoin et al (2007) } \\
\text { Rocco and Morabito (2016) } \\
\text { Banasik et al. (2016) } \\
\text { Jamshidi and Osanloo (2018) } \\
\text { Villalba and Dimitrakopoulos (2016) } \\
\text { Goodfellow and Dimitrakopoulos (2017) } \\
\text { Liao et al. (2017) } \\
\text { Aydin et al. (2018) } \\
\text { Belluco et al. (2015) } \\
\text { Heydari and Ghasemi (2018) } \\
\text { Jindal and Sangwan (2017) }\end{array}$ & $\begin{array}{l}\text { Mundi et al (2013) } \\
\text { Rajaram et al (2002) } \\
\text { Gupta et al (2011) } \\
\text { Wazed et al (2011) } \\
\text { Mitra (2009) } \\
\text { Khor et al (2008) } \\
\text { Ribas et al (2010) } \\
\text { Tarhan et al (2011) } \\
\text { Tong et al (2012) } \\
\text { Wang et al (2010) } \\
\text { Zanjani et al (2010a) } \\
\text { Zanjani et al (2010b) } \\
\text { Zanjani et al (2011) } \\
\text { Zanjani et al (2013a) } \\
\text { Zanjani et al (2013b) } \\
\text { Radulescu et al (2008) } \\
\text { Ravi (1998) } \\
\text { Xiao et al (2012) } \\
\text { Beaudoin et al (2007) } \\
\text { Mundi et al (2016) } \\
\text { Jindal and Sangwan (2017) }\end{array}$ & $\begin{array}{l}\text { Duenyas et al (2000) } \\
\text { Pendharkart (1997) } \\
\text { Kannegiesser et al (2009) } \\
\text { Xiao et al (2012) }\end{array}$ \\
\hline $\begin{array}{l}\text { Subtype value } \\
\text { (S.Value) }\end{array}$ & Kannegiesser et al (2009) & Radulescu et al (2008) & Kannegiesser et al (2009) \\
\hline $\begin{array}{l}\text { Subtype state } \\
\text { (S.State) }\end{array}$ & $\begin{array}{l}\text { Miller et al (1997) } \\
\text { Beaudoin et al (2007) }\end{array}$ & $\begin{array}{l}\text { Bohle et al (2010) } \\
\text { Beaudoin et al (2007) } \\
\text { Begen et al (2003) } \\
\text { Sel et al. (2017) }\end{array}$ & Sel and Bloemhof-Ruwaard (2017) \\
\hline
\end{tabular}

Figure 6. Distribution of the reviewed papers according to modelling approach and uncertainty modelling.

\begin{tabular}{|l|r|r|r|r|r|r|r|r|}
\hline $\begin{array}{l}\text { Modeling approach/ } \\
\text { Uncertainty modeling }\end{array}$ & LP & MOLP & NLP & SP & FP & HYB & TOTAL & $\begin{array}{c}\text { TOTAL } \\
(\%)\end{array}$ \\
\hline Scenario-based approach & 15 & 1 & 4 & 33 & & 3 & 56 & $64 \%$ \\
\hline Distribution-based approach & & 1 & 6 & 4 & & & 11 & $13 \%$ \\
\hline Fuzzy-based approach & 4 & 3 & 1 & 2 & 9 & 1 & 20 & $23 \%$ \\
\hline TOTAL & 19 & 5 & 11 & 39 & 9 & 4 &
\end{tabular}


Figure 7. Distribution of the reviewed papers according to sector, LHP uncertainty, uncertainty approach and modelling approach.

\begin{tabular}{|c|c|c|c|c|c|c|c|c|c|c|c|c|c|c|}
\hline \multirow[b]{2}{*}{ Sector } & \multirow{2}{*}{$\begin{array}{c}\text { no. } \\
\text { papers } \\
\text { Total }\end{array}$} & \multirow{2}{*}{$\begin{array}{c}\text { no. } \\
\text { papers } \\
\text { LHP } \\
\text { uncert. }\end{array}$} & \multicolumn{3}{|c|}{ LHP Characteristic vs LHP uncertainty } & \multicolumn{3}{|c|}{ Uncertainty approach } & \multicolumn{6}{|c|}{ Modelling approach } \\
\hline & & & $\begin{array}{c}\text { LHP } \\
\text { Characteristic }\end{array}$ & $\begin{array}{c}\text { Theoretical } \\
\text { LHP } \\
\text { Characteristic }\end{array}$ & $\begin{array}{c}\text { LHP } \\
\text { uncertainty }\end{array}$ & Distr. & Scenario & Fuzzy & LP & SP & NLP & MOLP & FP & HYB \\
\hline \multirow{4}{*}{ Petroleum } & \multirow{4}{*}{16} & \multirow{4}{*}{9} & S. & $\mathrm{X}$ & & & & & & & & & & \\
\hline & & & S.Qty & $\mathrm{X}$ & 9 & & 8 & 1 & 1 & 6 & 1 & 1 & & \\
\hline & & & S.Value & $X$ & & & & & & & & & & \\
\hline & & & S.State & & & & & & & & & & & \\
\hline \multirow{5}{*}{ Agri-food } & \multirow{5}{*}{20} & \multirow{5}{*}{14} & S. & $X$ & & & & & & & & & & \\
\hline & & & S.Qty & $\mathrm{X}$ & 8 & 1 & 7 & & 3 & 2 & 1 & 1 & & 1 \\
\hline & & & S.Value & $\mathrm{X}$ & & & & & & & & & & \\
\hline & & & S.State & $X$ & 5 & & 4 & 1 & 2 & 2 & & & & 1 \\
\hline & & & S.Qty \& S.Value & $\mathrm{X}$ & 1 & 1 & & & & & & 1 & & \\
\hline \multirow{4}{*}{ Remanufacturing } & \multirow{4}{*}{20} & \multirow{4}{*}{13} & S. & $X$ & & & & & & & & & & \\
\hline & & & S. Qty & $\mathrm{X}$ & 13 & 5 & 6 & 2 & 2 & 4 & 5 & 1 & 1 & \\
\hline & & & S.Value & $X$ & & & & & & & & & & \\
\hline & & & S.State & $X$ & & & & & & & & & & \\
\hline \multirow{5}{*}{ Wood } & \multirow{5}{*}{7} & \multirow{5}{*}{6} & S. & $X$ & & & & & & & & & & \\
\hline & & & S.Qty & $X$ & 5 & & 5 & & & 5 & & & & \\
\hline & & & S.Value & $X$ & & & & & & & & & & \\
\hline & & & S.State & $X$ & & & & & & & & & & \\
\hline & & & S.Qty \& S.State & & 1 & & 1 & & 1 & & & & & \\
\hline \multirow{4}{*}{ Mining } & \multirow{4}{*}{9} & \multirow{4}{*}{9} & S. & $X$ & & & & & & & & & & \\
\hline & & & S.Qty & $\mathrm{X}$ & 9 & 1 & 4 & 4 & 2 & 3 & 2 & & 2 & \\
\hline & & & S.Value & $\mathrm{X}$ & & & & & & & & & & \\
\hline & & & S.State & & & & & & & & & & & \\
\hline \multirow{5}{*}{ Ceramics } & \multirow{5}{*}{3} & \multirow{5}{*}{2} & S. & $X$ & & & & & & & & & & \\
\hline & & & S.Qty & $X$ & & & & & & & & & & \\
\hline & & & S.Value & $X$ & & & & & & & & & & \\
\hline & & & S.State & & & & & & & & & & & \\
\hline & & & S. \& S. Qty & $\mathrm{X}$ & 2 & & 1 & 1 & 1 & & & & 1 & \\
\hline & & & S. & $X$ & & & & & & & & & & \\
\hline & & & S.Qty & $X$ & 6 & 2 & 3 & 1 & 1 & 4 & & & & 1 \\
\hline & & & S.Value & $\mathrm{X}$ & & & & & & & & & & \\
\hline Others & 12 & 8 & S.State & $X$ & & & & & & & & & & \\
\hline & & & S. \& S. Qty & $X$ & 1 & & & 1 & & & & & 1 & \\
\hline & & & S.Qty \& S.Value & $\mathrm{X}$ & 1 & & 1 & & 1 & & & & & \\
\hline TOTAL & 87 & 61 & & & 61 & 10 & 40 & 11 & 14 & 26 & 9 & 4 & 5 & 3 \\
\hline
\end{tabular}


Figure 8. Conceptual model

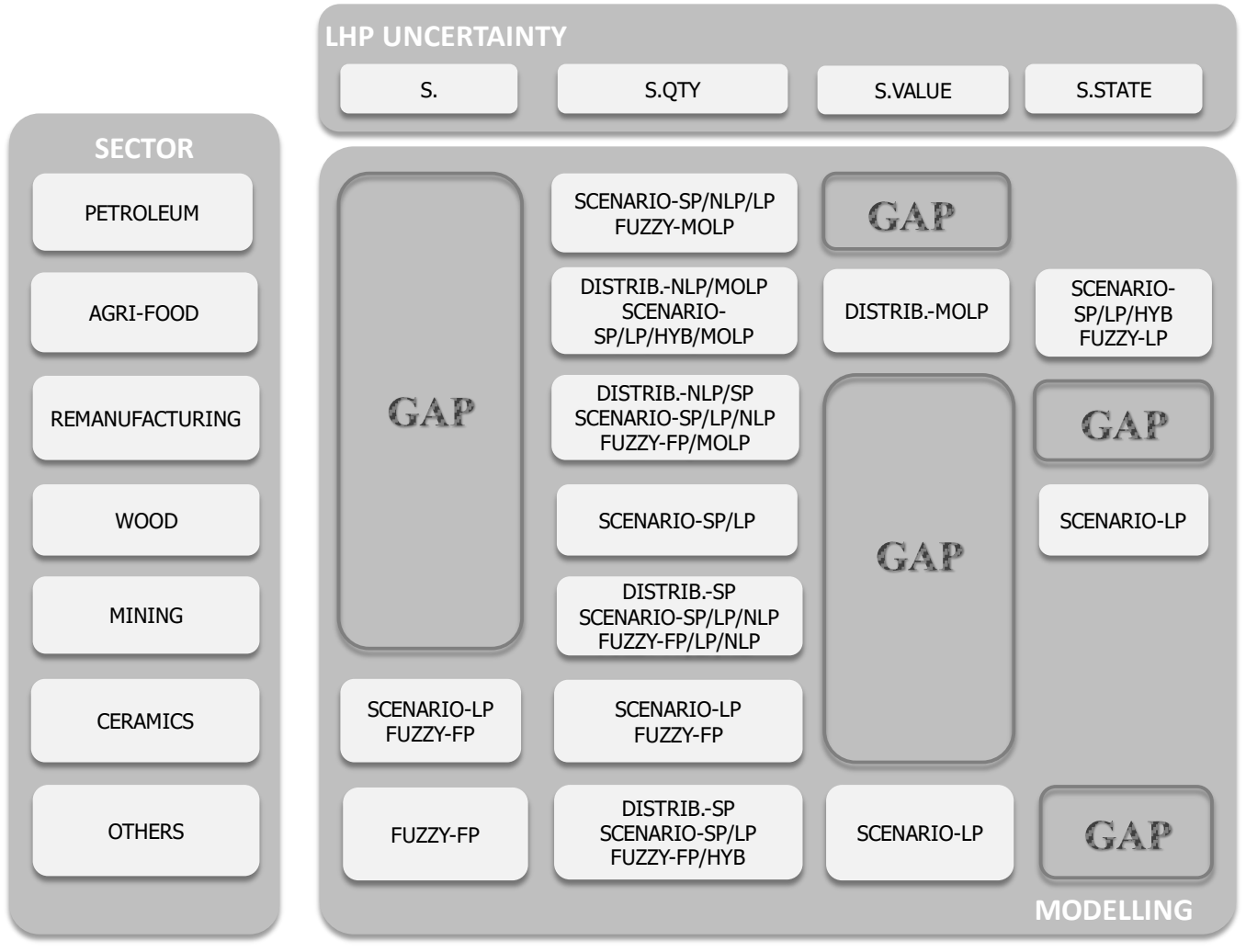




\section{TABLES}

Table 1. Classification of the reviewed papers according to the proposed analysis framework (Petroleum).

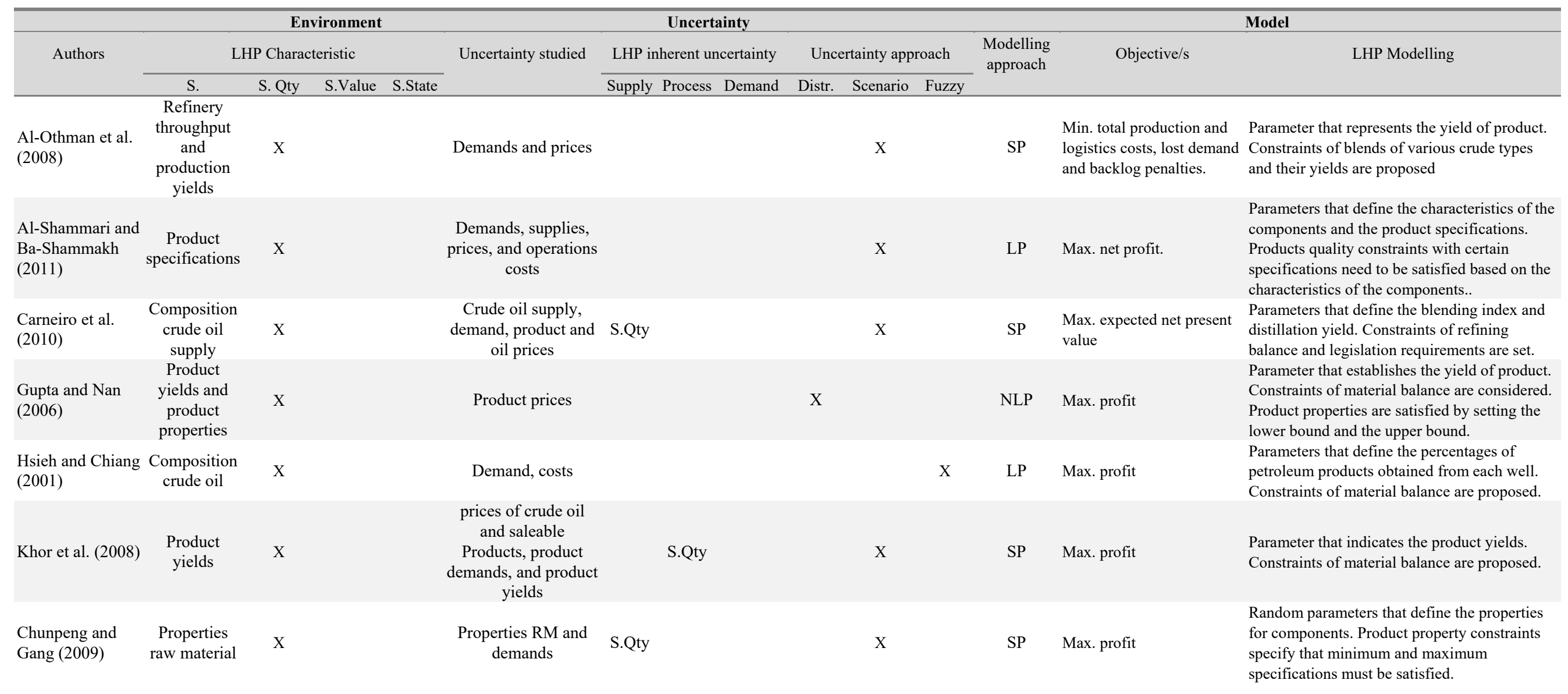




\begin{tabular}{|c|c|c|c|c|c|c|c|c|c|c|c|c|c|c|}
\hline \multirow{3}{*}{ Authors } & \multicolumn{4}{|c|}{ Environment } & \multicolumn{7}{|c|}{ Uncertainty } & \multicolumn{3}{|r|}{ Model } \\
\hline & \multicolumn{4}{|c|}{ LHP Characteristic } & \multirow[t]{2}{*}{ Uncertainty studied } & \multicolumn{3}{|c|}{ LHP inherent uncertainty } & \multicolumn{3}{|c|}{ Uncertainty approach } & \multirow[t]{2}{*}{$\begin{array}{l}\text { Modelling } \\
\text { approach }\end{array}$} & \multirow[t]{2}{*}{ Objective/s } & \multirow[t]{2}{*}{ LHP Modelling } \\
\hline & S. & S. Qty & S.Value & S.State & & Supply & Process & Demand & Distr. & Scenario & Fuzzy & & & \\
\hline $\begin{array}{l}\text { Pongsakdi et al. } \\
\text { (2006) }\end{array}$ & $\begin{array}{l}\text { Properties of } \\
\text { intermediates }\end{array}$ & $\mathrm{X}$ & & & $\begin{array}{c}\text { Demand and product } \\
\text { prices }\end{array}$ & & & & & $\mathrm{X}$ & & LP & Max. profit & $\begin{array}{l}\text { Parameters that define the properties for } \\
\text { products. Constraints of material balance are } \\
\text { considered and quality constraints specify that } \\
\text { minimum and maximum specifications must be } \\
\text { satisfied. }\end{array}$ \\
\hline $\begin{array}{l}\text { Ravi and Reddy } \\
\text { (1998) }\end{array}$ & $\begin{array}{l}\text { Splitting } \\
\text { processes }\end{array}$ & $\mathrm{X}$ & & & $\begin{array}{l}\text { Profit } \\
\text { Capacity }\end{array}$ & & S.Qty & & & & $\mathrm{X}$ & MOLP & $\begin{array}{l}\text { Max. ratio (profit/capacity } \\
\text { of the primary unit) } \\
\text { Max. ratio (profit/capacity } \\
\text { of the cracker) }\end{array}$ & $\begin{array}{l}\text { Parameters that indicate the yields in the } \\
\text { splitting process. Mass balance constraints are } \\
\text { set. }\end{array}$ \\
\hline $\begin{array}{l}\text { Ribas et al. } \\
\text { (2010) }\end{array}$ & $\begin{array}{l}\text { Composition } \\
\text { FG (density } \\
\text { and } \\
\text { viscosity) }\end{array}$ & $\mathrm{X}$ & & & $\begin{array}{l}\text { Crude oil supply, } \\
\text { demand, product and } \\
\text { oil prices }\end{array}$ & & S.Qty & & & $\mathrm{X}$ & & SP & Max. profit & $\begin{array}{l}\text { Parameters that define the limit the sulphur } \\
\text { content and the viscosity of the final products. } \\
\text { Environmental constraints must be satisfied. }\end{array}$ \\
\hline $\begin{array}{l}\text { Tarhan et al. } \\
\text { (2011) }\end{array}$ & $\begin{array}{l}\text { Yield of } \\
\text { process }\end{array}$ & $\mathrm{X}$ & & & $\begin{array}{l}\text { Initial maximum oil, } \\
\text { recoverable oil or gas } \\
\text { volume, and water } \\
\text { breakthrough time }\end{array}$ & & S.Qty & & & $\mathrm{X}$ & & NLP & Max. net present value & $\begin{array}{l}\text { Parameters that represent the yields of } \\
\text { processes. Constraints that describe the input- } \\
\text { output relationships for the processes are } \\
\text { proposed. }\end{array}$ \\
\hline $\begin{array}{l}\text { Wang and Zheng } \\
\text { (2010) }\end{array}$ & $\begin{array}{l}\text { Production } \\
\text { yields }\end{array}$ & $\mathrm{X}$ & & & $\begin{array}{l}\text { Inventory costs, } \\
\text { production yield and } \\
\text { inventory level }\end{array}$ & & S.Qty & & & $\mathrm{X}$ & & LP & Min. total production costs & $\begin{array}{l}\text { Parameter that represents the yield of } \\
\text { production. Constraints of material balance are } \\
\text { considered. }\end{array}$ \\
\hline $\begin{array}{l}\text { Zhang et al. } \\
\text { (2012) }\end{array}$ & $\begin{array}{l}\text { Sulphur } \\
\text { content for } \\
\text { the blended } \\
\text { oil }\end{array}$ & $\mathrm{X}$ & & & Delivery delay RM & & & & & $\mathrm{X}$ & & NLP & Max. total profit & $\begin{array}{l}\text { The sulphur content is expressed by the } \\
\text { property-based flexibility index that depend on } \\
\text { the upper and lower bounds the sulphur- } \\
\text { content. Constraint sulphur balance is set. }\end{array}$ \\
\hline $\begin{array}{l}\text { Leiras et al. } \\
\text { (2013) }\end{array}$ & $\begin{array}{c}\text { Composition } \\
\text { FG }\end{array}$ & $\mathrm{X}$ & & & $\begin{array}{l}\text { Demand, oil prices, } \\
\text { and product prices }\end{array}$ & & & & & $\mathrm{X}$ & & SP & Max. expected margin & $\begin{array}{l}\text { Parameters that define the limit the sulphur } \\
\text { content and the viscosity of the final products. } \\
\text { Environmental constraints must be satisfied. }\end{array}$ \\
\hline $\begin{array}{l}\text { Zimberg and } \\
\text { Testuri (2006) }\end{array}$ & $\begin{array}{l}\text { Composition } \\
\text { crude oil } \\
\text { supply } \\
\text { (density and } \\
\text { viscosity) } \\
\end{array}$ & $\mathrm{X}$ & & & $\begin{array}{l}\text { Demand of a kind of } \\
\text { product (ifo) }\end{array}$ & S.Qty & & & & $\mathrm{X}$ & & SP & Max. net benefit & $\begin{array}{l}\text { Parameters that define the density and viscosity } \\
\text { of crudes and products. Density and viscosity } \\
\text { constraints are considered and specification } \\
\text { constraints specify that minimum and } \\
\text { maximum specifications must be satisfied. }\end{array}$ \\
\hline $\begin{array}{c}\text { TOTAL } \\
\%\end{array}$ & & $\begin{array}{c}16 \text { of } 16 \\
100 \%\end{array}$ & $\begin{array}{c}0 \text { of } 16 \\
0 \%\end{array}$ & $\begin{array}{c}0 \text { of } 16 \\
0 \%\end{array}$ & & 3 & 6 & 0 & $\begin{array}{c}1 \text { of } 16 \\
6 \%\end{array}$ & $\begin{array}{c}13 \text { of } 16 \\
81 \%\end{array}$ & $\begin{array}{c}2 \text { of } 16 \\
13 \%\end{array}$ & & & \\
\hline
\end{tabular}


Table 2. Classification of the reviewed papers according to the proposed analysis framework (Agri-food sector).

\begin{tabular}{|c|c|c|c|c|c|c|c|c|c|c|c|c|c|c|}
\hline \multirow{3}{*}{ Authors } & \multirow{2}{*}{\multicolumn{4}{|c|}{$\begin{array}{l}\text { Environment } \\
\text { LHP Characteristic }\end{array}$}} & \multicolumn{7}{|c|}{ Uncertainty } & \multicolumn{3}{|r|}{ Model } \\
\hline & & & & & \multirow[t]{2}{*}{ Uncertainty studied } & \multicolumn{3}{|c|}{ LHP inherent uncertainty } & \multicolumn{3}{|c|}{ Uncertainty approach } & \multirow{2}{*}{$\begin{array}{l}\text { Modelling } \\
\text { approach }\end{array}$} & \multirow[t]{2}{*}{ Objective/s } & \multirow[t]{2}{*}{ LHP Modelling } \\
\hline & S. & S. Qty & S.Value & S.State & & Supply & Process & Demand & Distr. & Scenario & Fuzzy & & & \\
\hline $\begin{array}{l}\text { Radulescu et al. } \\
\text { (2008) }\end{array}$ & $\begin{array}{l}\text { Yields and } \\
\text { market prices }\end{array}$ & $\mathrm{X}$ & $\mathrm{X}$ & & $\begin{array}{l}\text { Yields and market } \\
\text { prices }\end{array}$ & & $\begin{array}{l}\text { S.Qty } \\
\text { S.Value }\end{array}$ & & $\mathrm{X}$ & & & MOLP & $\begin{array}{l}\text { Min. average loss } \\
\text { Max. expected } \\
\text { return } \\
\text { Min. financial risk }\end{array}$ & $\begin{array}{l}\text { Random parameters that define the yields and market } \\
\text { prices. Yields constraints specify the inferior bound } \\
\text { for the expected yield. Market prices are considered in } \\
\text { the objective function. }\end{array}$ \\
\hline $\begin{array}{l}\text { Ahumada et al. } \\
\text { (2012) }\end{array}$ & $\begin{array}{l}\text { Quality } \\
\text { products, } \\
\text { crop yields, } \\
\text { perishable } \\
\text { product }\end{array}$ & $\mathrm{X}$ & & $\mathrm{X}$ & $\begin{array}{l}\text { Crop prices and crop } \\
\text { yields }\end{array}$ & S.Qty & & & & $\mathrm{X}$ & & SP & Max. revenue & $\begin{array}{l}\text { Quality is defined by a parameter indicating the } \\
\text { percentage of harvested fruits with a given colour. } \\
\text { Constraints establish maximum storage time and the } \\
\text { maximum colour accepted by the customer. } \\
\text { Stochastic parameters define the crops' yield and the } \\
\text { market prices. Constraints of material balance are set } \\
\text { and perishability is taken account by a loss function } \\
\text { for the decay of the products in the objective function. }\end{array}$ \\
\hline $\begin{array}{l}\text { Miller et al. } \\
\text { (1997) }\end{array}$ & $\begin{array}{l}\text { Perishable } \\
\text { product }\end{array}$ & & & $\mathrm{X}$ & $\begin{array}{l}\text { Harvest time, tomato } \\
\text { packing rate, and } \\
\text { shortage cost. }\end{array}$ & S.State & & & & & $\mathrm{X}$ & LP & $\begin{array}{l}\text { Min. total packing } \\
\text { cost }\end{array}$ & $\begin{array}{l}\text { Constraints that are for the period to-period balance of } \\
\text { the matured unharvested fields. }\end{array}$ \\
\hline $\begin{array}{l}\text { Tan and Çömden } \\
(2012)\end{array}$ & Yield harvest & $\mathrm{X}$ & & & $\begin{array}{l}\text { Yield, demand and } \\
\text { harvest }\end{array}$ & S.Qty & & & $\mathrm{X}$ & & & NLP & $\begin{array}{l}\text { Max. total expected } \\
\text { profit }\end{array}$ & $\begin{array}{l}\text { Normal random parameters that define the crop yields } \\
\text { and are included in the objective function. }\end{array}$ \\
\hline $\begin{array}{l}\text { Bohle et al. } \\
(2010)\end{array}$ & $\begin{array}{l}\text { Quality loss } \\
\text { function }\end{array}$ & & & $\mathrm{X}$ & Labour availability & & S.State & & & $\mathrm{X}$ & & SP & Min. total costs & $\begin{array}{l}\text { The quality cost is included in the objective function } \\
\text { expressed as a penalty on the price of the grapes by a } \\
\text { quality loss factor. Constraint of productivity } \\
\text { requirement is posed. }\end{array}$ \\
\hline $\begin{array}{l}\text { Guan and } \\
\text { Philpott (2011) }\end{array}$ & $\begin{array}{l}\text { Perishable } \\
\text { product }\end{array}$ & & & $\mathrm{X}$ & Milk supply & & & & & $\mathrm{X}$ & & SP & Min. costs & $\begin{array}{l}\text { An index defines the perishable products. Constraint } \\
\text { that limits the refrigerated storage of perishable } \\
\text { products is proposed. }\end{array}$ \\
\hline $\begin{array}{l}\text { Bertrand and } \\
\text { Rutten (1999) }\end{array}$ & $\begin{array}{l}\text { Raw } \\
\text { materials } \\
\text { features in } \\
\text { finish goods }\end{array}$ & $\mathrm{X}$ & & & $\begin{array}{l}\text { Demand, } \\
\text { Raw materials quality }\end{array}$ & S.Qty & & & & $\mathrm{X}$ & & SP & Min. expected costs & $\begin{array}{l}\text { Parameters that define the fraction of property in RM } \\
\text { and the lower bound and upper bound of the property } \\
\text { in the FG. Constraints of material balance are } \\
\text { proposed. }\end{array}$ \\
\hline $\begin{array}{l}\text { Hovelaque et al. } \\
\text { (2009) }\end{array}$ & $\begin{array}{l}\text { Raw } \\
\text { materials } \\
\text { features }\end{array}$ & $\mathrm{X}$ & & & Product prices & & & & & $\mathrm{X}$ & & HYB & Max expected profit & $\begin{array}{l}\text { Parameters that define the fat content and protein } \\
\text { content in raw materials and in the product types. } \\
\text { Constraints of material balance are set. }\end{array}$ \\
\hline
\end{tabular}




\begin{tabular}{|c|c|c|c|c|c|c|c|c|c|c|c|c|c|c|}
\hline \multirow{3}{*}{ Authors } & \multirow{2}{*}{\multicolumn{4}{|c|}{$\begin{array}{r}\text { Environment } \\
\text { LHP Characteristic }\end{array}$}} & \multicolumn{7}{|c|}{ Uncertainty } & \multicolumn{3}{|r|}{ Model } \\
\hline & & & & & \multirow[t]{2}{*}{ Uncertainty studied } & \multicolumn{3}{|c|}{ LHP inherent uncertainty } & \multicolumn{3}{|c|}{ Uncertainty approach } & \multirow{2}{*}{$\begin{array}{l}\text { Modelling } \\
\text { approach }\end{array}$} & \multirow[t]{2}{*}{ Objective/s } & \multirow[t]{2}{*}{ LHP Modelling } \\
\hline & S. & S. Qty & S.Value & S.State & & Supply & Process & Demand & Distr. & Scenario & Fuzzy & & & \\
\hline $\begin{array}{l}\text { Begen and } \\
\text { Puterman (2003) }\end{array}$ & $\begin{array}{l}\text { Types, } \\
\text { grades, } \\
\text { perishability }\end{array}$ & $X$ & & $X$ & Capacities & & S.State & & & $\mathrm{X}$ & & LP & Max. total profit & $\begin{array}{l}\text { Parameter that establishes the supply of type of fish } \\
\text { species. Constraints of inventory balance are set. } \\
\text { Parameters that define the probability of deteriorating. } \\
\text { Fish deterioration constraint is proposed. }\end{array}$ \\
\hline $\begin{array}{l}\text { Randhawa and } \\
\text { Bjarnason (1995) }\end{array}$ & $\begin{array}{l}\text { Composition } \\
\text { of raw } \\
\text { materials, } \\
\text { freshness }\end{array}$ & $\mathrm{X}$ & & $X$ & $\begin{array}{l}\text { Quantity and } \\
\text { composition of raw } \\
\text { materials }\end{array}$ & S.Qty & & & & $\mathrm{X}$ & & HYB & Max. net revenues & $\begin{array}{l}\text { Parameters that establish the amount of product } \\
\text { produced from the available fish species. Constraints } \\
\text { of material balance are considered. } \\
\text { Constraint that limits the number of days in stock. }\end{array}$ \\
\hline $\begin{array}{l}\text { Schutz and } \\
\text { Tomasgard } \\
(2011)\end{array}$ & $\begin{array}{l}\text { Splitting } \\
\text { process }\end{array}$ & $\mathrm{X}$ & & & Demand & & & & & $\mathrm{X}$ & & SP & $\begin{array}{l}\text { Max. expected } \\
\text { profits }\end{array}$ & $\begin{array}{l}\text { Parameter defines the yield of splitting process. } \\
\text { Constraint of material balance is proposed. }\end{array}$ \\
\hline $\begin{array}{l}\text { Paksoy et al. } \\
\text { (2012) }\end{array}$ & $\begin{array}{l}\text { Waste oil } \\
\text { (wax) to } \\
\text { recycling }\end{array}$ & $\mathrm{X}$ & & & $\begin{array}{l}\text { Capacities and } \\
\text { demands }\end{array}$ & & & & & & $\mathrm{X}$ & FP & Min. transport costs & $\begin{array}{l}\text { Parameter that specifies the amount of transported } \\
\text { waste oil. Constraint of material balance is } \\
\text { considered. }\end{array}$ \\
\hline $\begin{array}{l}\text { Albornoz et al. } \\
\text { (2014) }\end{array}$ & $\begin{array}{l}\text { Raw } \\
\text { materials } \\
\text { quality and } \\
\text { perishability }\end{array}$ & $\mathrm{X}$ & & $X$ & Raw materials quality & S.Qty & & & & $\mathrm{X}$ & & LP & Max. net profit & $\begin{array}{l}\text { An index defines the shelf-life each item. Constraint } \\
\text { that determines the amount of product to be frozen. } \\
\text { A parameter specifies raw materials quality by } \\
\text { different cutting patterns. Constraint that calculates } \\
\text { the total amount of product, retrieved from all the } \\
\text { cutting patterns are proposed. }\end{array}$ \\
\hline $\begin{array}{l}\text { Bakhrankova et } \\
\text { al. (2014) }\end{array}$ & $\begin{array}{l}\text { Raw } \\
\text { materials } \\
\text { quality and } \\
\text { perishability }\end{array}$ & $\mathrm{X}$ & & $\mathrm{X}$ & $\begin{array}{l}\text { Market prices and } \\
\text { amount of raw } \\
\text { material incoming }\end{array}$ & & & & & $\mathrm{X}$ & & SP & $\begin{array}{l}\text { Max. operational } \\
\text { profit }\end{array}$ & $\begin{array}{l}\text { Parameters that specify the quality of fish types and } \\
\text { the shelf-life of product. Constraints of material } \\
\text { balance including raw material that has expired and } \\
\text { FIFO constraints are considered. }\end{array}$ \\
\hline $\begin{array}{l}\text { Pauls-Worm et } \\
\text { al. (2014) }\end{array}$ & Perishability & & & $X$ & Demand & & & & $X$ & & & $\mathrm{SP}$ & $\begin{array}{l}\text { Min. total expected } \\
\text { costs }\end{array}$ & $\begin{array}{l}\text { An index defines the age of each item. FIFO } \\
\text { constraints makes sure that demand is fulfilled first by } \\
\text { the oldest items in stock. Items out-dated are } \\
\text { considered waste. }\end{array}$ \\
\hline $\begin{array}{l}\text { Munhoz and } \\
\text { Morabito (2014) }\end{array}$ & $\begin{array}{l}\text { Raw } \\
\text { materials } \\
\text { features } \\
\text { (acidity) }\end{array}$ & $\mathrm{X}$ & & & Base acidity & S.Qty & & & & $\mathrm{X}$ & & LP & Min. total costs & $\begin{array}{l}\text { Parameters that define the maximum and minimum } \\
\text { acidity. Constraints that ensure the maximum and } \\
\text { minimum acidity limit for each final product from the } \\
\text { supplied oranges variety are proposed. }\end{array}$ \\
\hline $\begin{array}{l}\text { Sel and Bloemhof- } \\
\text { Ruwaard (2017) }\end{array}$ & $\begin{array}{l}\text { Perishability } \\
\quad \text { of } \\
\text { intermediate } \\
\text { products }\end{array}$ & & & $\mathrm{X}$ & $\begin{array}{l}\text { quality decay of } \\
\text { intermediate mixture }\end{array}$ & & S.State & & & $\mathrm{X}$ & & HYB & $\begin{array}{l}\text { Min the production } \\
\text { makespan }\end{array}$ & $\begin{array}{l}\text { Lifetime parameter, represented by Weibull } \\
\text { distribution, that limits the storage duration of } \\
\text { intermediate mixture by means of perishability } \\
\text { constraints }\end{array}$ \\
\hline
\end{tabular}




\begin{tabular}{|c|c|c|c|c|c|c|c|c|c|c|c|c|c|c|}
\hline \multirow{3}{*}{ Authors } & \multicolumn{4}{|c|}{ Environment } & \multicolumn{7}{|c|}{ Uncertainty } & \multicolumn{3}{|r|}{ Model } \\
\hline & \multicolumn{4}{|c|}{ LHP Characteristic } & \multirow[t]{2}{*}{ Uncertainty studied } & \multicolumn{3}{|c|}{ LHP inherent uncertainty } & \multicolumn{3}{|c|}{ Uncertainty approach } & \multirow{2}{*}{$\begin{array}{l}\text { Modelling } \\
\text { approach }\end{array}$} & \multirow[t]{2}{*}{ Objective/s } & \multirow[t]{2}{*}{ LHP Modelling } \\
\hline & S. & S. Qty & S.Value & S.State & & Supply & Process & Demand & Distr. & Scenario & Fuzzy & & & \\
\hline Sel et al. (2017) & Food waste & & & $\mathrm{X}$ & Demand & & & S.State & & $\mathrm{X}$ & & SP & Min. total costs & $\begin{array}{l}\text { Constraints that calculate the expected waste amounts } \\
\text { by multiplying the demand probability with the } \\
\text { difference between demand and delivery }\end{array}$ \\
\hline $\begin{array}{l}\text { Rocco and } \\
\text { Morabito (2016) }\end{array}$ & $\begin{array}{l}\text { Crop yield } \\
\text { and soluble } \\
\text { solids content }\end{array}$ & $\mathrm{X}$ & & & $\begin{array}{l}\text { Crop yield and soluble } \\
\text { solids content }\end{array}$ & S.Qty & & & & $\mathrm{X}$ & & LP & $\begin{array}{l}\text { Min. the main } \\
\text { production and } \\
\text { logistics costs }\end{array}$ & $\begin{array}{l}\text { Parameters that define the crop yield and soluble } \\
\text { solids content. Constraints of material balance are } \\
\text { proposed. }\end{array}$ \\
\hline $\begin{array}{l}\text { Banasik et al. } \\
\text { (2016) }\end{array}$ & $\begin{array}{l}\text { Mushrooms } \\
\text { size and } \\
\text { quality }\end{array}$ & $\mathrm{X}$ & & & $\begin{array}{l}\text { Mushroom yield, } \\
\text { demand and prices }\end{array}$ & S.Qty & & & & $\mathrm{X}$ & & MOLP & $\begin{array}{l}\text { Min. costs } \\
\text { Max. growers profit } \\
\text { Min. environmental } \\
\text { impact }\end{array}$ & $\begin{array}{l}\text { Parameter that indicates the mushroom yield. } \\
\text { Constraints of material balance are set. }\end{array}$ \\
\hline $\begin{array}{c}\text { TOTAL } \\
\%\end{array}$ & & $\begin{array}{c}14 \text { of } 20 \\
70 \%\end{array}$ & $\begin{array}{c}1 \text { of } 20 \\
5 \%\end{array}$ & $\begin{array}{c}11 \text { of } 20 \\
55 \%\end{array}$ & & 9 & 5 & 1 & $\begin{array}{c}3 \text { of } 20 \\
15 \%\end{array}$ & $\begin{array}{c}15 \text { of } 20 \\
75 \%\end{array}$ & $\begin{array}{c}2 \text { of } 20 \\
10 \%\end{array}$ & & & \\
\hline
\end{tabular}

Table 3. Classification of the reviewed papers according to the proposed analysis framework (Remanufacturing).

\begin{tabular}{|c|c|c|c|c|c|c|c|c|c|c|c|c|c|}
\hline \multirow{3}{*}{ Authors } & \multicolumn{4}{|c|}{ Environment } & \multicolumn{6}{|c|}{ Uncertainty } & \multicolumn{3}{|c|}{ Model } \\
\hline & \multicolumn{4}{|c|}{ LHP Characteristic } & \multirow[t]{2}{*}{ Uncertainty studied } & \multicolumn{2}{|c|}{ LHP inherent uncertainty } & \multicolumn{3}{|c|}{ Uncertainty approach } & \multirow{2}{*}{$\begin{array}{l}\text { Modelling } \\
\text { approach }\end{array}$} & \multirow[t]{2}{*}{ Objective/s } & \multirow[t]{2}{*}{ LHP Modelling } \\
\hline & S. & S. Qty & S.Value & S.State & & Supply Process & Demand & Distr. & Scenario & Fuzzy & & & \\
\hline Aras et al. (2004) & $\begin{array}{l}\text { Quality of } \\
\text { returns }\end{array}$ & $\mathrm{X}$ & & & $\begin{array}{l}\text { Demand, quantity and } \\
\text { quality of returns }\end{array}$ & S.Qty & & $\mathrm{X}$ & & & SP & Min. long-run operating cost & $\begin{array}{l}\text { Quality of the returned items follows a } \\
\text { Poisson distribution. Inventory balance } \\
\text { constraint is proposed. }\end{array}$ \\
\hline $\begin{array}{l}\text { Benedito and } \\
\text { Corominas (2010) }\end{array}$ & $\begin{array}{l}\text { Quality of } \\
\text { returns }\end{array}$ & $\mathrm{X}$ & & & $\begin{array}{l}\text { Quality and quantity of } \\
\text { returns }\end{array}$ & S.Qty & & $\mathrm{X}$ & & & NLP & $\begin{array}{l}\text { Min. expected cost in each } \\
\text { period }\end{array}$ & $\begin{array}{l}\text { Parameter that represents the probability that } \\
\text { the product will be returned. Constraints of } \\
\text { material balance are set. }\end{array}$ \\
\hline $\begin{array}{l}\text { Denizel et al. } \\
\text { (2010) }\end{array}$ & $\begin{array}{l}\text { Quality of } \\
\text { returns }\end{array}$ & $\mathrm{X}$ & & & Quality of returns & S.Qty & & & $\mathrm{X}$ & & SP & Max. expected profit. & $\begin{array}{l}\text { Parameter that defines the probability of } \\
\text { return with a specific quality. Inventory } \\
\text { balance constraints are proposed. }\end{array}$ \\
\hline Dong et al. (2011) & $\begin{array}{l}\text { Quality of } \\
\text { returns }\end{array}$ & $\mathrm{X}$ & & & $\begin{array}{l}\text { Quality, arriving time, } \\
\text { and process time of } \\
\text { returns }\end{array}$ & S.Qty & & & $\mathrm{X}$ & & LP & Max. total net profit & $\begin{array}{l}\text { Parameters that define the number of new } \\
\text { products and the number of remanufactured } \\
\text { products to meet the demand of each group. } \\
\text { Constraints of material balance are } \\
\text { considered. }\end{array}$ \\
\hline
\end{tabular}




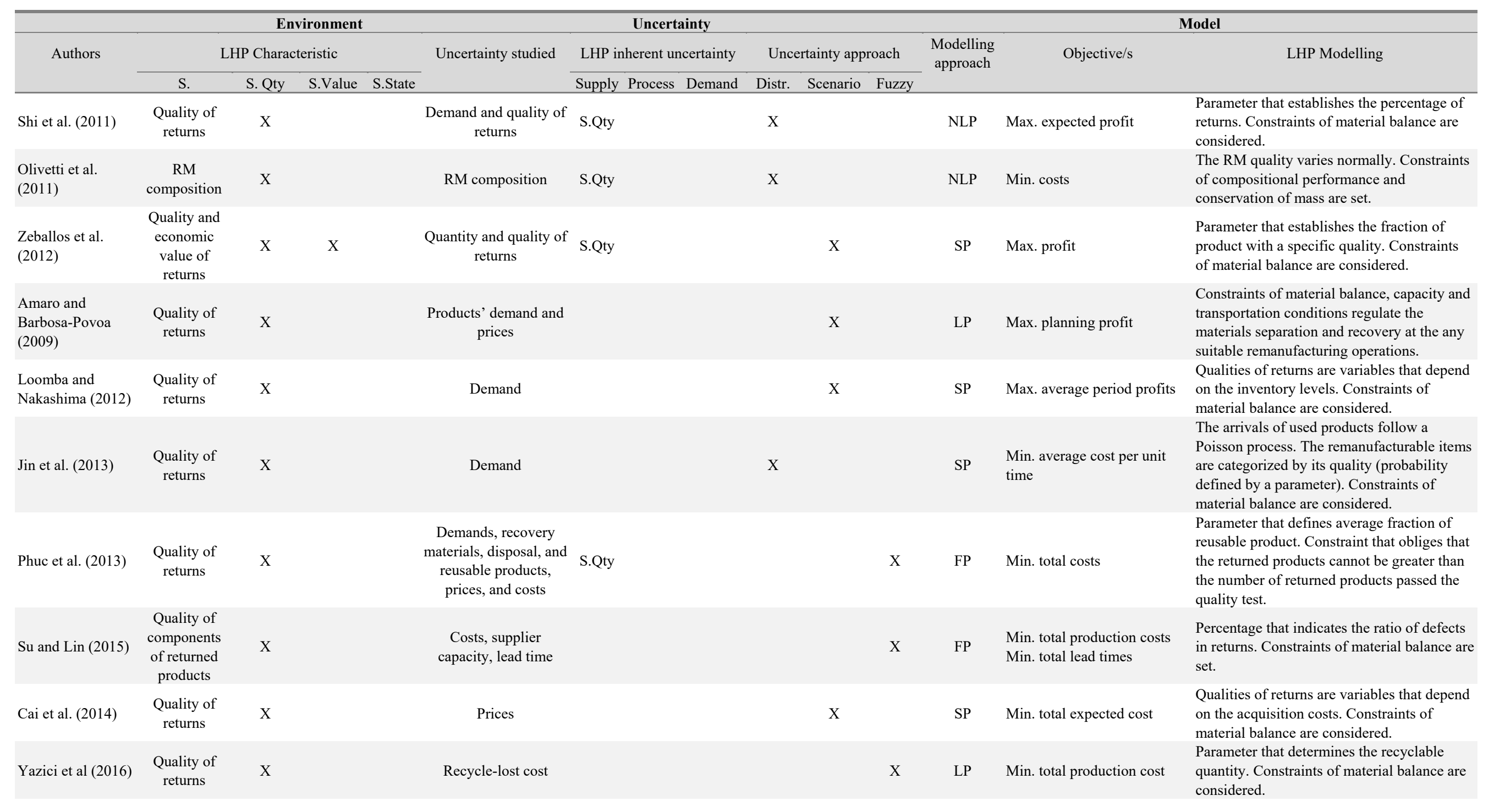




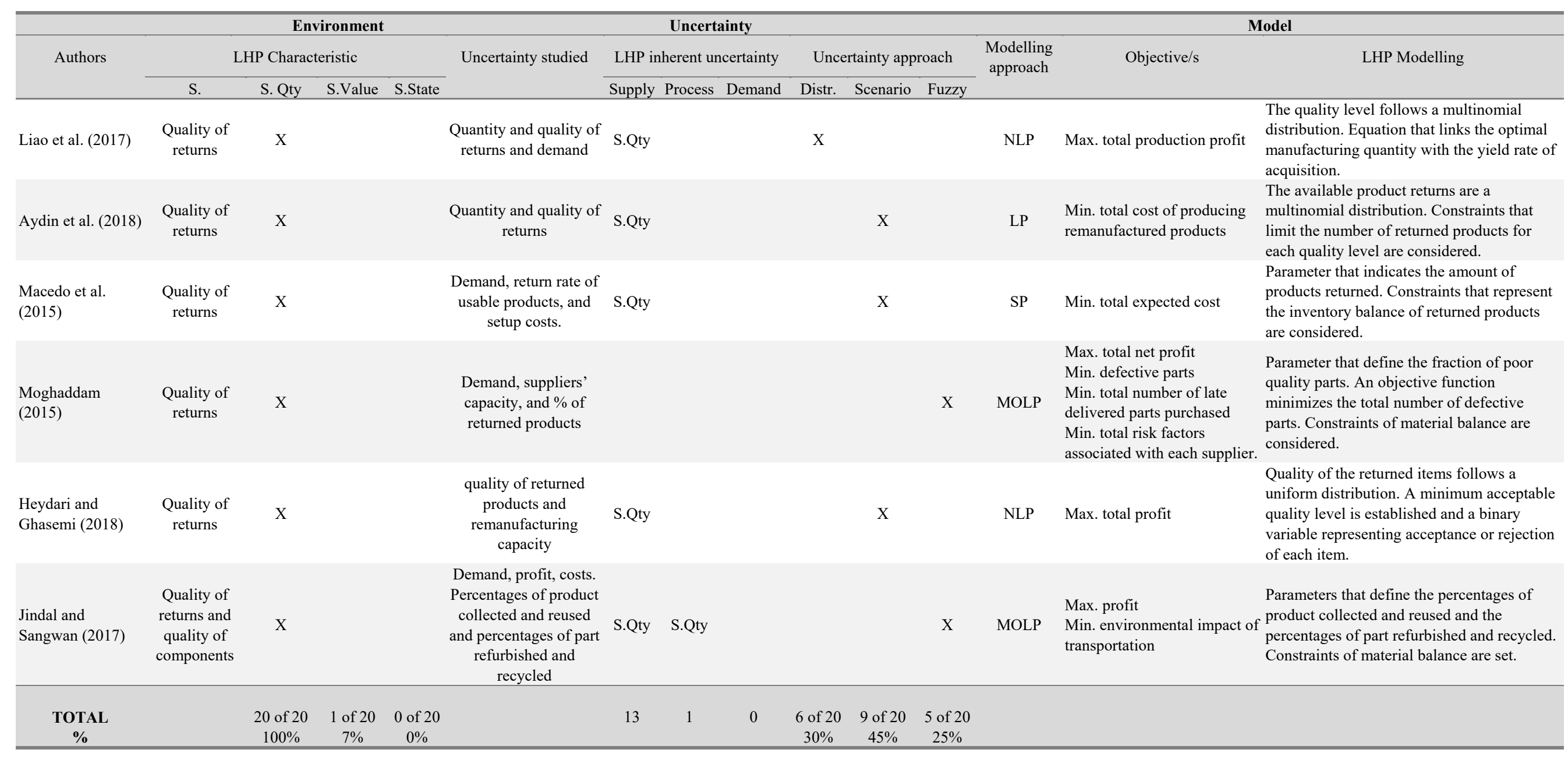


Table 4. Classification of the reviewed papers according to the proposed analysis framework (Wood).

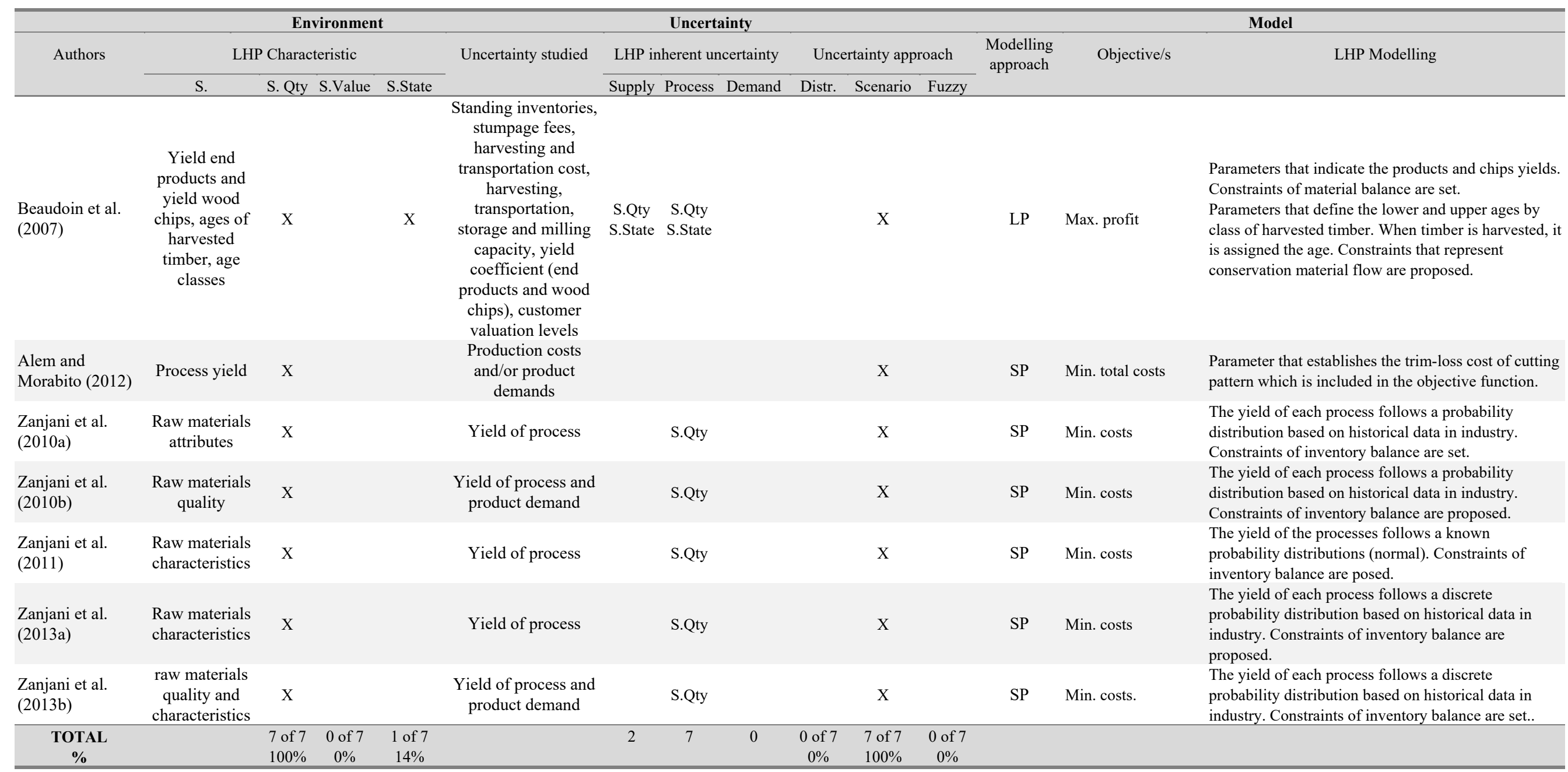


Table 5. Classification of the reviewed papers according to the proposed analysis framework (Mining).

\begin{tabular}{|c|c|c|c|c|c|c|c|c|c|c|c|c|c|c|}
\hline \multirow{3}{*}{ Authors } & \multirow{2}{*}{\multicolumn{4}{|c|}{$\begin{array}{r}\text { Environment } \\
\text { LHP Characteristic }\end{array}$}} & \multicolumn{7}{|c|}{ Uncertainty } & \multicolumn{3}{|r|}{ Model } \\
\hline & & & & & \multirow[t]{2}{*}{ Uncertainty studied } & \multicolumn{3}{|c|}{ LHP inherent uncertainty } & \multicolumn{3}{|c|}{ Uncertainty approach } & \multirow{2}{*}{$\begin{array}{l}\text { Modelling } \\
\text { approach }\end{array}$} & \multirow[t]{2}{*}{ Objective/s } & \multirow[t]{2}{*}{ LHP Modelling } \\
\hline & S. & S. Qty & S.Value & S.State & & Supply & Process & Demand & Distr. & Scenario & Fuzzy & & & \\
\hline $\begin{array}{l}\text { Rico-Ramirez et } \\
\text { al. (2009) }\end{array}$ & Ore quality & $\mathrm{X}$ & & & Ore quality & S.Qty & & & & $\mathrm{X}$ & & SP & Max. profit & $\begin{array}{l}\text { Parameter that represents the ore quality. } \\
\text { Constraints of material balance with grade } \\
\text { minimum required are established. }\end{array}$ \\
\hline $\begin{array}{l}\text { Chakraborty and } \\
\text { Chandra (2005) }\end{array}$ & $\begin{array}{l}\text { Quality: raw } \\
\text { coal grades }\end{array}$ & $X$ & & & $\begin{array}{l}\text { Composition RM } \\
\text { (\%Ash), yield (input- } \\
\text { output), cost RM }\end{array}$ & S.Qty & & & & & $\mathrm{X}$ & FP & $\begin{array}{l}\text { Optimal levels of raw coal } \\
\text { of different grades to } \\
\text { achieve desired } \\
\text { specifications }\end{array}$ & $\begin{array}{l}\text { The relationships among the desired } \\
\text { specifications of products and the proportion of } \\
\text { raw coal have been obtained by multiple linear } \\
\text { regression analysis. Constraints of the upper } \\
\text { and lower limits of the storage capacity are } \\
\text { established for each grade of raw coal. }\end{array}$ \\
\hline $\begin{array}{l}\text { Pendharkar } \\
\text { (1997) }\end{array}$ & Qualities & $X$ & & & $\begin{array}{l}\text { Level of quality and } \\
\text { profitability }\end{array}$ & & & S.Qty & & & $\mathrm{X}$ & LP & Max. total net profit & $\begin{array}{l}\text { Parameters that define quality attributes. } \\
\text { Quality constraints must be satisfied for each } \\
\text { market. }\end{array}$ \\
\hline $\begin{array}{l}\text { Pendharkar } \\
(2013)\end{array}$ & Coal quality & $\mathrm{X}$ & & & $\begin{array}{l}\text { Profit and coal } \\
\text { quality }\end{array}$ & S.Qty & & & & & $\mathrm{X}$ & FP & Max. profit and quality & $\begin{array}{l}\text { Parameters that establish coal quality. Quality } \\
\text { constraints must be satisfied for each market. }\end{array}$ \\
\hline Mitra (2009) & $\begin{array}{l}\text { Grindability } \\
\text { Sharpness }\end{array}$ & $X$ & & & $\begin{array}{l}\text { Grindability indices } \\
\text { Sharpness indices }\end{array}$ & & S.Qty & & & & $\mathrm{X}$ & NLP & Max. throughput & $\begin{array}{l}\text { Parameters that define the percentages of } \\
\text { passing for the each size class. Constraints of } \\
\text { material balance with their grades maximum } \\
\text { and minimum allowable are established. }\end{array}$ \\
\hline $\begin{array}{l}\text { Jamshidi and } \\
\text { Osanloo (2018) }\end{array}$ & Ore quality & $\mathrm{X}$ & & & Ore grade and tonnage & S.Qty & & & & $\mathrm{X}$ & & LP & Max. profit & $\begin{array}{l}\text { Parameters that define the percentages of } \mathrm{Fe}, \mathrm{S} \\
\text { and } \mathrm{P} \text {. Constraints of material balance with } \\
\text { their grades maximum and minimum allowable } \\
\text { are established. }\end{array}$ \\
\hline $\begin{array}{l}\text { Matamoros \& } \\
\text { Dimitrakopoulos } \\
\text { (2016) }\end{array}$ & Ore quality & $\mathrm{X}$ & & & $\begin{array}{l}\text { Ore quantity and } \\
\text { quality and equipment } \\
\text { availability }\end{array}$ & S.Qty & & & & $\mathrm{X}$ & & SP & Min. total mining cost & $\begin{array}{l}\text { Parameters that define the variation ranges of } \\
\text { ore quality. Quality constraints are considered } \\
\text { to meet the quality conditions. }\end{array}$ \\
\hline
\end{tabular}




\begin{tabular}{|c|c|c|c|c|c|c|c|c|c|c|c|c|c|c|}
\hline \multirow{3}{*}{ Authors } & \multicolumn{4}{|c|}{ Environment } & \multicolumn{7}{|c|}{ Uncertainty } & \multicolumn{3}{|r|}{ Model } \\
\hline & \multicolumn{4}{|c|}{ LHP Characteristic } & \multirow[t]{2}{*}{ Uncertainty studied } & \multicolumn{3}{|c|}{ LHP inherent uncertainty } & \multicolumn{3}{|c|}{ Uncertainty approach } & \multirow{2}{*}{$\begin{array}{l}\text { Modelling } \\
\text { approach }\end{array}$} & \multirow[t]{2}{*}{ Objective/s } & \multirow[t]{2}{*}{ LHP Modelling } \\
\hline & S. & S. Qty & S.Value & S.State & & Supply & Process & Demand & Distr. & Scenario & Fuzzy & & & \\
\hline $\begin{array}{l}\text { Goodfellow and } \\
\text { Dimitrakopoulos } \\
\text { (2017) }\end{array}$ & Ore quality & $X$ & & & Ore grades & S.Qty & & & & $\mathrm{X}$ & & NLP & Max. net present value & $\begin{array}{l}\text { Parameters that define the ore attributes } \\
\text { (quality). Product quality constraints with their } \\
\text { grades maximum and minimum allowable are } \\
\text { established. }\end{array}$ \\
\hline $\begin{array}{c}\text { TOTAL } \\
\%\end{array}$ & & $\begin{array}{l}9 \text { of } 9 \\
100 \%\end{array}$ & $\begin{array}{c}0 \text { of } 9 \\
0 \%\end{array}$ & $\begin{array}{c}0 \text { of } 9 \\
0 \%\end{array}$ & & 7 & 1 & 1 & $\begin{array}{c}1 \text { of } 9 \\
11 \%\end{array}$ & $\begin{array}{l}4 \text { of } 9 \\
44.5 \%\end{array}$ & $\begin{array}{l}4 \text { of } 9 \\
44.5 \%\end{array}$ & & & \\
\hline
\end{tabular}

Table 6. Classification of the reviewed papers according to the proposed analysis framework (Ceramics)

\begin{tabular}{|c|c|c|c|c|c|c|c|c|c|c|c|c|c|c|}
\hline \multirow{3}{*}{ Authors } & \multicolumn{4}{|c|}{ Environment } & \multicolumn{7}{|c|}{ Uncertainty } & \multicolumn{3}{|r|}{ Model } \\
\hline & \multicolumn{4}{|c|}{ LHP Characteristic } & \multirow[t]{2}{*}{ Uncertainty studied } & \multicolumn{3}{|c|}{ LHP inherent uncertainty } & \multicolumn{3}{|c|}{ Uncertainty approach } & \multirow{2}{*}{$\begin{array}{l}\text { Modelling } \\
\text { approach }\end{array}$} & \multirow[t]{2}{*}{ Objective/s } & \multirow[t]{2}{*}{ LHP Modelling } \\
\hline & S. & S. Qty & S.Value & S.State & & Supply & Process & Demand & Distr. & Scenario & Fuzzy & & & \\
\hline $\begin{array}{l}\text { Mundi et al. } \\
\text { (2013) }\end{array}$ & $\begin{array}{l}\text { Homogeneous } \\
\text { sublots }\end{array}$ & $\mathrm{X}$ & & & $\begin{array}{l}\text { Homogeneous } \\
\text { Sublots }\end{array}$ & & $\begin{array}{l}\text { S. } \\
\text { S.Qty }\end{array}$ & & & $\mathrm{X}$ & & LP & Max. gross margin & $\begin{array}{l}\text { Parameters that express the percentage of each } \\
\text { planned lot which is homogeneous. Constraints that } \\
\text { reflect the division of a specific lot into homogeneous } \\
\text { sub-lots are set. }\end{array}$ \\
\hline $\begin{array}{l}\text { Peidro et al. } \\
(2012)\end{array}$ & $\begin{array}{l}\text { First quality } \\
\text { finished goods }\end{array}$ & $\mathrm{X}$ & & & $\begin{array}{l}\text { Gross margin, idle } \\
\text { time, backorder } \\
\text { quantities }\end{array}$ & & & & & & $\mathrm{X}$ & FP & $\begin{array}{l}\text { Max. degree of } \\
\text { satisfaction of three } \\
\text { objective function } \\
\text { (gross margin, } \\
\text { backlogged demand, } \\
\text { idle time). }\end{array}$ & $\begin{array}{l}\text { Parameter that represent the percentage of first quality } \\
\text { products. Constraint of material balance is considered. }\end{array}$ \\
\hline $\begin{array}{l}\text { Mundi et al. } \\
\text { (2016) }\end{array}$ & $\begin{array}{l}\text { Homogeneus } \\
\text { sublots }\end{array}$ & $\mathrm{X}$ & & & $\begin{array}{l}\text { Homogeneous Sublots } \\
\text { and customer order } \\
\text { size }\end{array}$ & & $\begin{array}{l}\text { S. } \\
\text { S.Qty }\end{array}$ & S. Qty & & & $\mathrm{X}$ & FP & Max. profit & $\begin{array}{l}\text { Parameters that express the percentage of each } \\
\text { planned lot considered homogeneous. Constraints that } \\
\text { reflects the division of a specific lot into } \\
\text { homogeneous sub-lots are posed. }\end{array}$ \\
\hline $\begin{array}{l}\text { TOTAL } \\
\%\end{array}$ & & $\begin{array}{l}3 \text { of } 3 \\
100 \%\end{array}$ & $\begin{array}{c}0 \text { of } 3 \\
0 \%\end{array}$ & $\begin{array}{c}0 \text { of } 3 \\
0 \%\end{array}$ & & 0 & 4 & 0 & $\begin{array}{c}0 \text { of } 3 \\
0 \%\end{array}$ & $\begin{array}{l}1 \text { of } 3 \\
33 \%\end{array}$ & $\begin{array}{c}2 \text { of } 3 \\
67 \%\end{array}$ & & & \\
\hline
\end{tabular}


Table 7. Classification of the reviewed papers according to the proposed analysis framework (Other sectors).

\begin{tabular}{|c|c|c|c|c|c|c|c|c|c|c|c|c|c|c|}
\hline \multirow{3}{*}{ Authors } & \multirow{2}{*}{\multicolumn{4}{|c|}{$\begin{array}{r}\text { Environment } \\
\text { LHP Characteristic }\end{array}$}} & \multicolumn{7}{|c|}{ Uncertainty } & \multicolumn{3}{|r|}{ Model } \\
\hline & & & & & \multirow[t]{2}{*}{ Uncertainty studied } & \multicolumn{3}{|c|}{ LHP inherent uncertainty } & \multicolumn{3}{|c|}{ Uncertainty approach } & \multirow{2}{*}{$\begin{array}{l}\text { Modelling } \\
\text { approach }\end{array}$} & \multirow[t]{2}{*}{ Objective/s } & \multirow[t]{2}{*}{ LHP Modelling } \\
\hline & S. & S. Qty & S.Value & S.State & & Supply & Process & Demand & Distr. & Scenario & Fuzzy & & & \\
\hline $\begin{array}{l}\text { Kannegiesser et al. } \\
(2009)\end{array}$ & $\begin{array}{l}\text { Raw material } \\
\text { consumption } \\
\text { and price } \\
\text { ranges }\end{array}$ & $\mathrm{X}$ & $\mathrm{X}$ & & $\begin{array}{l}\text { Prices and quantities } \\
\text { of finished goods } \\
\text { and raw materials }\end{array}$ & $\begin{array}{l}\text { S.Qty } \\
\text { S.Value }\end{array}$ & & $\begin{array}{l}\text { S.Qty } \\
\text { S.Value }\end{array}$ & & $\mathrm{X}$ & & LP & Max. profit & $\begin{array}{l}\text { Parameters that define the linear recipe function for } \\
\text { product-resource combination. Constraint of material } \\
\text { balance is proposed. } \\
\text { Parameters that indicate the price ranges for each } \\
\text { product-location combination which are included in } \\
\text { the objective function. }\end{array}$ \\
\hline Karabuk (2008) & $\begin{array}{l}\text { Yarn end } \\
\text { products (sku) }\end{array}$ & $\mathrm{X}$ & & & Demand & & & & & $\mathrm{X}$ & & SP & Min. total costs & $\begin{array}{l}\text { Parameter that defines the production rate depending } \\
\text { on blends. Constraint of material balance is set. }\end{array}$ \\
\hline Wu et al. (2010) & $\begin{array}{l}\text { Quality } \\
\text { grades in } \\
\text { assemblies } \\
\text { and finished } \\
\text { goods }\end{array}$ & $\mathrm{X}$ & & & $\begin{array}{l}\text { Price and demand of } \\
\text { finished goods }\end{array}$ & & & & & $\mathrm{X}$ & & SP & Max. total profit & $\begin{array}{l}\text { Parameters that indicate the production yield rate and } \\
\text { assembly yield rate by quality-grades. Constraints of } \\
\text { the inventory flow equilibrium are included. }\end{array}$ \\
\hline $\begin{array}{l}\text { Rastogi et al. } \\
\text { (2011) }\end{array}$ & $\begin{array}{l}\text { Sort stage and } \\
\text { test stage } \\
\text { yield }\end{array}$ & $\mathrm{X}$ & & & Demand & & & & & $\mathrm{X}$ & & SP & Max. total profit & $\begin{array}{l}\text { Parameters that define the yield fractions at sort stage } \\
\text { and yield of products at testing operations. } \\
\text { Constraints of network flow are posed. }\end{array}$ \\
\hline $\begin{array}{l}\text { Rong and } \\
\text { Lahdelma (2008) }\end{array}$ & $\begin{array}{l}\text { Raw materials } \\
\text { composition }\end{array}$ & $\mathrm{X}$ & & & $\begin{array}{l}\text { Raw materials } \\
\text { composition and } \\
\text { final product } \\
\text { composition }\end{array}$ & $\begin{array}{l}\text { S. } \\
\text { S.Qty }\end{array}$ & & & & & $\mathrm{X}$ & FP & $\begin{array}{l}\text { Min. raw material } \\
\text { costs }\end{array}$ & $\begin{array}{l}\text { Parameters that specify the yield of raw materials and } \\
\text { the lower and upper bounds for use of raw material. } \\
\text { Constraints stating that alloying elements from scrap } \\
\text { materials together with that from pure alloying } \\
\text { materials must meet the standard of the final product } \\
\text { and constraints of the overall mass balances are set. }\end{array}$ \\
\hline $\begin{array}{l}\text { Duenyas and Tsai } \\
(2000)\end{array}$ & $\begin{array}{l}\text { Quality FG, } \\
\text { quality yields }\end{array}$ & $\mathrm{X}$ & & & $\begin{array}{l}\text { Quality FG, demand, } \\
\text { production times, } \\
\text { quality yields }\end{array}$ & & & S.Qty & $\mathrm{X}$ & & & SP & $\begin{array}{l}\text { Max. long-run } \\
\text { average profit }\end{array}$ & $\begin{array}{l}\text { Parameters that represent the probability of obtaining } \\
\text { products with a certain level of quality and demanded } \\
\text { by differentiated customers. }\end{array}$ \\
\hline $\begin{array}{l}\text { Gupta and } \\
\text { Grossmann (2011) }\end{array}$ & Yields & $\mathrm{X}$ & & & Yields & & S.Qty & & & $\mathrm{X}$ & & SP & $\begin{array}{l}\text { Min. total expected } \\
\text { cost }\end{array}$ & $\begin{array}{l}\text { Parameters that specify the random yield of the } \\
\text { processes. Generic constraints of balance is set. }\end{array}$ \\
\hline
\end{tabular}




\begin{tabular}{|c|c|c|c|c|c|c|c|c|c|c|c|c|c|c|}
\hline \multirow{3}{*}{ Authors } & \multicolumn{4}{|c|}{ Environment } & \multicolumn{7}{|c|}{ Uncertainty } & \multicolumn{3}{|r|}{ Model } \\
\hline & \multicolumn{4}{|c|}{ LHP Characteristic } & \multirow[t]{2}{*}{ Uncertainty studied } & \multicolumn{3}{|c|}{ LHP inherent uncertainty } & \multicolumn{3}{|c|}{ Uncertainty approach } & \multirow{2}{*}{$\begin{array}{l}\text { Modelling } \\
\text { approach }\end{array}$} & \multirow[t]{2}{*}{ Objective/s } & \multirow[t]{2}{*}{ LHP Modelling } \\
\hline & S. & S. Qty & S.Value & S.State & & Supply & Process & Demand & Distr. & Scenario & Fuzzy & & & \\
\hline $\begin{array}{l}\text { Wang and Zhang } \\
\text { (2006) }\end{array}$ & $\begin{array}{l}\text { Internal } \\
\text { quality and } \\
\text { assembled } \\
\text { quality }\end{array}$ & $X$ & & & Due date & & & & & & $\mathrm{X}$ & FP & $\begin{array}{l}\text { Max. degree of } \\
\text { satisfaction of the } \\
\text { due date asked by } \\
\text { the customer. }\end{array}$ & $\begin{array}{l}\text { Parameters that define internal quality and assembled } \\
\text { quality. Constraints that indicate that the obtained } \\
\text { quality should meet the condition of quality asked by } \\
\text { the customer. }\end{array}$ \\
\hline $\begin{array}{l}\text { Wazed et al. } \\
\text { (2011) }\end{array}$ & $\begin{array}{l}\text { Defective } \\
\text { items }\end{array}$ & $\mathrm{X}$ & & & $\begin{array}{l}\text { Quality and } \\
\text { breakdown }\end{array}$ & & S.Qty & & & $\mathrm{X}$ & & LP & Min. costs & $\begin{array}{l}\text { Parameter that establishes the percentage of defective } \\
\text { items. Constraints of material requirement are set. }\end{array}$ \\
\hline Xiao et al. (2012) & $\begin{array}{c}\text { Imperfect } \\
\text { quality } \\
\text { (quality } \\
\text { disturbances } \\
\text { of users, } \\
\text { suppliers, } \\
\text { manufacturers } \\
\text { and } \\
\text { distributors) }\end{array}$ & $\mathrm{X}$ & & & $\begin{array}{l}\text { Imperfect quality } \\
\text { (quality disturbances } \\
\text { of users, suppliers, } \\
\text { manufacturers and } \\
\text { distributors) }\end{array}$ & S.Qty & S.Qty & S.Qty & & & $\mathrm{X}$ & HYB & $\begin{array}{l}\text { Min. impact of } \\
\text { quality uncertainties. }\end{array}$ & $\begin{array}{l}\text { Parameters that define the quality disturbances of } \\
\text { users, suppliers, manufacturers and distributors. } \\
\text { Constraints are proposed by means of transfer } \\
\text { functions. }\end{array}$ \\
\hline
\end{tabular}

